\title{
EL COMISO DE GANANCIAS
}

\author{
Confiscation of proceeds
}

Ignacio Ananias Zaror

Resumen: El presente artículo tiene como finalidad determinar, producto de la falta de una previsión general sobre las ganancias o provechos en el Código Penal, el alcance del término «efectos» del artículo 31, con el fin de probar que aquellas se encuentran contenidas dentro de estos. Lo precedente, a su vez, con el objeto de extender el ámbito de aplicación de la pena de comiso, tradicionalmente muy restringido tanto por la doctrina como por la práctica jurisprudencial chilena. Antes de efectuar lo anterior, se realizará un análisis descriptivo del comiso en el derecho español y alemán, cuyo alcance, como se probará, es similar al de la legislación general chilena.

Palabras Clave: Comiso - efectos - ganancias - "enriquecimiento sin causa" "criminalidad organizada".

Abstract: In the absence of a general regulation regarding gains or profits in the Criminal Code, this paper intends to determine the scope of the term "effects" as provided in article 31, in order to prove that gains or profits are included in such disposition. The objective is to expand the application of the penalty of confiscation, traditionally restricted by Chilean authorities. Before this, a descriptive analysis of confiscation will be held in both Spanish and German law. The scope, as will be demonstrated, it is similar to the Chilean general legislation.

Keywords: Confiscation - effects - gains - "unjust enrichment" -"organized crime".

\section{Introducción $^{1}$}

\begin{abstract}
Nuestros antecesores, los germanos, casi no admitian más que las penas pecuniarias. Aquellos hombres libres y guerreros estimaban que su sangre no debia ser derramada más que con las armas en la mano. Los japoneses, por el contrario, rechazan este tipo de penas, con el pretexto de que los ricos eludirian el castigo. Pero, ¿acaso los ricos no temen perder sus bienes? ¿No podrían ponerse penas pecuniarias en proporción con las fortunas?
\end{abstract}

(Montesquieu, Del espiritu de las leyes. Capítulo XVIII)

\footnotetext{
* Profesor invitado de Derecho Penal, Universidad Adolfo Ibáñez; correo electrónico: ignacio.ananias@gmail.com.

1 Agradezco al profesor Antonio Bascuñán Rodríguez por su permanente e inestimable guía en la elaboración de una versión extensa de este trabajo. Asimismo, agradezco a Carlos Sánchez Rossi y a Sergio Faúndez Alarcón por sus valiosos comentarios a este documento.
}

Este artículo fue recibido el 2 de septiembre de 2013, siendo aprobada su publicación el 20 de agosto de 2014. 
En el sistema de penas del Código Penal chileno las consecuencias jurídicas pecuniarias impuestas por la realización de supuestos de normas de sanción desempeñan un rol bastante exiguo. En efecto, el eje del vigente código es sin duda el autor (=penas privativas de libertad), poseyendo "su" patrimonio solo un valor accesorio (fundamentalmente para la etapa de investigación).

Ciertas leyes especiales, sin embargo, al advertir que para enfrentar la criminalidad económica era insuficiente el escenario punitivo existente, crearon un repertorio más amplio de consecuencias jurídicas estatales, incluyendo, entre otras, el decomiso del provecho obtenido por o del hecho punible. De esto, no obstante, surge un problema axiomático. Al no tener el carácter de solución global, estas sanciones se aplican únicamente a dicho catálogo de delitos.

Al revisar la doctrina comparada, es usual encontrar la siguiente cita a la ONU para referirse al decomiso:

[A] rma estratégica, desincentivo económico total de la delincuencia organizada con el fin de obtener ganancias, y medio de identificar y de eliminar las ventajas financieras, $y$ el consiguiente poder de la conducta antisocial. ${ }^{2}$

Este entendimiento es consecuencia y fue antecedente, a la vez, de un fenómeno legislativo transversal al derecho comparado de la segunda mitad del siglo XX, el que tras reparar que mediante la criminalidad económica se obtenían provechos económicos cada vez más cuantiosos, que eran luego reintroducidos en el mercado formal (=legal), incorporó dentro de su repertorio punitivo el comiso de ganancias. Así, Alemania, que lo añadió como cláusula de aplicación general en 1975 (con la dictación del StGB). Posteriormente, se reprodujo ello en Suiza (1994, \59 schStGB), España (1995, artículo 127 CPE) y Austria (1996, \20 öStGB), entre otros países.

En Chile, como ya fue señalado, las leyes especiales muestran una evolución bastante semejante. De hecho, hay tres leyes paradigmáticas al respecto: (i) la Ley sobre Lavado y Blanqueo de Activos (19.913); (ii) la Ley sobre Tráfico Ilícito de Estupefacientes (20.000) y (iii) la Ley de Responsabilidad Penal de las

2 ORGANIZACIÓN DE NACIONES UNIDAS (1993), p. 15.

3 El artículo 27 de esta Ley, dentro de las sanciones que contempla, incluye las reglas de procedencia y alcance del comiso de la ley 20.000, la que en su artículo 45 dispone: "Sin perjuicio de las reglas generales, caerán especialmente en comiso [...] los efectos que de ellos provengan y las utilidades que bubieren originado, cualquiera que sea su naturaleza jurídica, o las transformaciones que bubieren experimentado [...]". 
Personas Jurídicas (20.393). ${ }^{4}$ La práctica judicial, sin embargo, ha demostrado que estas aún son insuficientes. ${ }^{5}$

De lo anterior surge tanto una certeza como una interrogante. La primera es que no existe una política criminal idónea para despojar a las organizaciones criminales de los provechos obtenidos de sus actividades ilícitas (no obstante la creación de organismos de prevención). Es decir, a pesar de la adopción de un repertorio de penas más amplio que el tradicional, la exacción de los beneficios obtenidos ilícitamente es bastante deficiente. Ello tiene como soporte que el proceso penal se dirige aún -en esencia- a la sanción del delito y no tanto a recobrar las ganancias obtenidas, así como también a la incapacidad (proporcional) del adjudicador para localizar estas. La incertidumbre, a su vez, corresponde al alcance del término «efectos» del artículo $31 \mathrm{CP}$, cuya importancia es amplia si se considera que aun en aquellos ámbitos en que existe una legislación extensiva de los objetos susceptibles de ser decomisados, se producen, en la práctica, enriquecimientos con antecedentes en esos hechos delictivos. Perviven, al respecto, dos posibles opciones: que estos solo cubren aquellos bienes originados en el delito (siendo, por tanto, dicha legislación especial la única esfera en que puede privarse al injustamente enriquecido de dichos activos) o, la tesis aquí defendida, que es posible interpretarlos de forma amplia, cubriendo tanto a aquellos, como también al objeto de la acción cuando este no pertenezca a terceros no responsables y a las ganancias obtenidas del delito, correspondiendo las disposiciones de las leyes especiales citadas, nada más que a una explicitación de las reglas generales.

\section{Regulación del comiso en el derecho penal comparado}

No obstante disponer de regulación especial y autárquica respecto del comiso de ganancias, es pertinente analizar los ordenamientos español y alemán, tanto para determinar el rendimiento de esta sanción, como para desentrañar si su incorporación expresa tardía en la regulación positiva significó su nacimiento o únicamente su explicitación (y escisión del término "efectos”).

\section{a) Derecho penal español}

La disposición central de la figura de comiso es el artículo $127 \mathrm{CPE}$, que corresponde al texto legal que lo regula con carácter general. Este forma parte del Libro I Título VI, que el legislador individualizó utilizando la locución "consecuencias accesorias".

\footnotetext{
${ }^{4}$ En su artículo 13 (2) dispone: "El producto del delito y demás bienes, efectos, objetos, documentos e instrumentos del mismo serán decomisados".

5 Por ejemplo, entre los años 2007 y 2011 se dictaron 42 condenas por lavado de activos. No obstante, solo en 19 de ellas (45\%) se impuso el decomiso de los instrumentos y efectos (productos inclusive) del delito. Véase UNIDAD DE ANÁLISIS FINANCIERO (2012), pp. 4-9.
} 
La legislación histórica casi de forma invariable asignó al comiso la naturaleza jurídica de pena accesoria. De hecho, únicamente el código de 1928 le atribuyó un carácter diverso (más propio de su ideología), correspondiente al de medidas de seguridad (artículo 90). La dictación del Código Penal de 1995 desencadenó la reforma más significativa a la hasta ese entonces pena de comiso. Esta modificó su naturaleza jurídica por la de "consecuencia accesoria", locución tomada de las Nebenfolgen (StGB), donde si bien la traducción es ajustada, las formas de reacción penal abarcadas por estas son diversas. En efecto, el StGB (Título I. "Penas", \45) comprende dentro de estas a la pérdida de la capacidad para desempeñar cargos públicos, de ser elegido para estos, así como la pérdida del derecho a sufragar; regulando al comiso, en cambio, en el Título VII en relación con el $\int 11 \mathrm{I} \mathrm{N}^{\circ} 8$, de las Maßnabmen (=medidas).

Asimismo, el código de 1995 se diferencia del anterior producto de la explicitación de la extensión del comiso a las ganancias provenientes del delito como cláusula de aplicación general, sin importar las transformaciones ulteriores que hubieren experimentado estas.

La reforma de la LO 15/2003 también fue bastante trascendente, ya que, entre otras medidas, amplió la sanción de comiso desde los instrumentos con que se ejecutó el delito a aquellos con que este se preparó; permitió su imposición aun en caso de que no se aplicare una pena y determinó que cuando deviniere en imposible el decomiso de los instrumentos, efectos y/o ganancias del delito (v. gr. por ocultamiento de la cosa), se impusiera un comiso de cosas por valor equivalente. Finalmente, con la LO 5/2010 nuevamente se modificó el régimen jurídico-penal del comiso, facultando ampliar su ámbito de aplicación, en los casos señalados por el legislador, a aquellas cosas que el sujeto pasivo de la sanción tenga en su patrimonio, previa constatación de una desproporción entre este (patrimonio) y los ingresos obtenidos legalmente.

\section{i) Naturaleza jurídica del comiso}

Como se señaló anteriormente, con la entrada en vigencia del Código Penal de 1995 se alteró de manera sustancial la regulación del comiso, el que mutó desde la calidad de pena [accesoria] (artículo 27 del Código Penal 1973) a la de "consecuencia accesoria" (artículo 127 del Código Penal de 1995). Esta decisión legislativa no es baladí, ya que determinó que la naturaleza jurídica de este no quede fijada con su sola inserción en el respectivo título, dejándola entregada, por tanto, a la tarea científica de la dogmática.

En función de esto último, Guinarte, ${ }^{6}$ Luzón, ${ }^{7}$ Conde-Pumpido, ${ }^{8}$ Ramón Ribas $^{9}$ y los fallos judiciales mayoritarios ${ }^{10}$ califican a esta figura como

${ }^{6}$ Guinarte (1996), p. 657. 
perteneciente a una tercera clase de sanciones penales, lo que se ve respaldado por el carácter de ley orgánica de la disposición que lo contiene, ${ }^{11}$ así como por el hecho de que es condición necesaria para su imposición la realización del supuesto de una norma de sanción (posdelictividad). Mirr $^{12}$ y García-Pablos, ${ }^{13}$ en cambio, en una postura cuyo rendimiento es inversamente proporcional a su delimitación, suscriben que el comiso "no se prevé como amenaza destinada a disuadir de la comisión del delito ni como castigo merecido por el delito", 14 así como tampoco busca prevenir otros hechos del sujeto peligroso, por lo que sostienen que este es una consecuencia accesoria de naturaleza particular (sui generis) cuya finalidad es únicamente privar al sujeto de los medios [peligrosos] con los que cometió el delito, o de los efectos económicos del mismo, ${ }^{15}$ Gracia Martín, a su vez, indica que el comiso es más bien una medida de carácter administrativo o de naturaleza civil en razón de que su fundamento es la "peligrosidad objetiva de determinadas cosas materiales y que se orientan a prevenir la utilización de las mismas en el futuro para la comisión de nuevos delitos" 16 (con independencia de quien tenga la tenencia de la cosa).

Las diversas [y opuestas] tomas de postura expuestas se ven amparadas en aquello que las tres coinciden, es decir, en la negación de una naturaleza de pena o de medida de seguridad del comiso, en atención a la no sujeción de este ni al principio de culpabilidad (exigencia de responsabilidad evoluciona hacia la de "tipo global" de injusto) ni al principio de personalidad (producto de su posible imposición a terceros no responsables).

Ahora bien, tradicionalmente la doctrina para determinar la naturaleza jurídica del comiso, lo descompone según sus distintas modalidades (diversidad que fundamenta la usual crítica doctrinaria respecto de su regulación conjunta). No obstante ello, coexisten las más dispares e inclusive opuestas opiniones dentro de la misma. En cuanto al comiso de efectos e instrumentos, Mapelli, ${ }^{17}$ Escuchurri ${ }^{18} \mathrm{y}$ Aguado ${ }^{19}$ suscriben que tiene una finalidad preventivo-situacional (=inocuización), que acarrea la expropiación de ciertos bienes en casos de sujetos que se vuelven peligrosos al momento de entrar en contacto con ellos. Se comprometen con una

\footnotetext{
${ }^{7}$ LUZÓN (2004), p. 545.

${ }^{8}$ CONDE-PuMPIDO (2004), p. 398.

${ }^{9}$ RAMÓN (2011), pp. 777-778.

10 STS 16/09, 27-1, en: CLIMENT (2011), p. 652.

11 PERIS/PLÀ: (2000), p. 952.

12 Mir (1998), p. 796.

13 GARCÍA-PABLOS (2005), pp. 148-149.

${ }^{14}$ Ibíd.

15 Mir (2004), p.3.

16 Gracia (2006), p. 562.

17 MAPELLI (1997), pp. 50-51.

18 ESCUCHURRI (2004), p. 11.

19 Aguado (2000), pp. 41-42.
} 
postura próxima a la enunciada, Peris/Plá, Puente, ${ }^{20}$ Mir y Faraldo, ${ }^{21}$ quienes no traspasan la peligrosidad de la cosa al sujeto, sino que fundamentan el comiso en una peligrosidad objetiva de la cosa en sí misma, "siendo una medida de aseguramiento de la colectividad frente al peligro de que se siga haciendo uso de ella para la comisión de nuevos delitos". ${ }^{22}$ Para la justificación del comiso por valor equivalente, sin embargo, devienen las precedentes teorías en insuficientes (cosa sustituta carece de dicha "peligrosidad"). ${ }^{23}$

En cuanto al comiso de ganancias, diferente al de instrumentos y efectos $-a$ priori porque estas no son peligrosas en sí mismas- Mapelli sostiene que posee por finalidad [únicamente] evitar un enriquecimiento injusto emanado del delito, razón por la cual lo califica como una figura contigua a la responsabilidad civil ${ }^{24}$ (no se compromete con ninguno de los fines de la pena). Así también Peris/Plá y Puente. Desaprueba lo anterior Aguado, quien sin negar que este cumple una función restitutoria/compensatoria, afirma su naturaleza de sanción penal, erigiendo su argumento en el disímil destino que tienen las ganancias decomisadas en ambos ordenamientos, en la no inserción del comiso en el título relativo a la responsabilidad civil derivada de los delitos, en su indudable finalidad preventiva y por ser impuesta por un órgano penal, estar prevista en una ley penal e ir unida a la imposición de una pena. Intensificaba la tesis de Aguado, Bacigalupo Saggese, ${ }^{25}$ quien atribuía al comiso (en sus dos modalidades) la naturaleza jurídica de pena, fundando su postura en el carácter accesorio [a la pena] -y no a la ejecución de la acción punible- que este revestía en el Código Penal de 1995. Aúna ambas posiciones Cazorla, quien repara en su finalidad de reponer una situación patrimonial conforme a Derecho y, asimismo, advierte su proximidad a la pena, en cuanto al privar de la ganancia al condenado "se le hace sentir con más fuerza la sanción del acto realizado". ${ }^{26}$

Serrano, ${ }^{27}$ en oposición a la doctrina tradicional, sostiene que cuando los instrumentos, efectos o ganancias del delito pertenezcan al condenado tiene el comiso una naturaleza sancionadora muy próxima a la de las penas accesorias. A su vez, le asigna una naturaleza coercitiva/administrativa en el caso de instrumentos y ciertos efectos; y civil, en el caso de ciertos efectos (distintos) y

\footnotetext{
20 PUENTE (2009), p. 6.

${ }^{21}$ FARALDO (2008), p. 5.

22 PERIS/Plá (2000), p. 952.

23 A no ser que se fundamente en la posibilidad de que el sujeto pasivo de la acción penal venda el bien sustituto para adquirir uno de semejantes características al primitivo [peligroso], lo que, a su vez, es manifiestamente criticable producto de que el límite de dicha argumentación es la confiscación.

${ }^{24}$ Llega a similar conclusión en Perú: GARCÍA (2006), p. 115. "Más adecuada a su naturaleza sería entender el decomiso de ganancias ilícitas como una medida civil de compensación con fines redistributivos, pues impide que el delito sea un título legítimo de adquisición de bienes o ganancias".

${ }^{25}$ BACigalupo (2002), p. 6.

${ }^{26}$ CAZORLA (2004), p. 81.

27 SERRANO (1998), pp. 873-874.
} 
ganancias, cuando el comiso se imponga por un hecho que, si bien, en principio reviste caracteres de delito, la responsabilidad penal no sea establecida por el tribunal. Fernández Pantoja, ${ }^{28}$ a su vez, no obstante adherir a la distinta naturaleza en atención a la modalidad pertinente, destaca que el comiso de efectos y de instrumentos es muy próximo a las medidas de seguridad (prevención de delitos futuros) y que el comiso de ganancias se aproxima a las penas, en razón de que se "pretende privar a quien ha cometido el delito de los beneficios obtenidos de forma ilícita", "proximidad", en ambos casos, que no acarrea la atribución de etiquetas fijas que desencadenen efectos político-criminales adversos, sino que permiten incluir dentro de ellas prácticamente a cualquier consecuencia jurídica. Adhiere a esta última postura, para el caso del comiso de instrumentos, Cazorla.

\section{ii) Comiso de instrumentos y efectos}

Para el código de 1973, Córdoba Roda ${ }^{30}$ (así como la doctrina mayoritaria) postulaba que únicamente eran efectos aquellos bienes que tenían su origen en el delito (v. gr. billetes falsificados) o que fueron transformados por el mismo (v. gr. alimentos adulterados), noción que excluye tanto al objeto de la acción como a las ganancias. Ello no es baladí si se observa que si bien el objeto de la acción generalmente pertenecerá a la víctima (v. gr. cosa hurtada o robada), habrá casos en que este será de propiedad del autor ${ }^{31}$ (v. gr. la remuneración obtenida producto de la venta ilícita de estupefacientes). Ratificaba lo anterior, una vez habiendo entrado en vigor el código de 1995, Guinarte, aduciendo que si el Código Penal señala explícitamente a las ganancias provenientes del delito entre los objetos del comiso, es consustancial a ello adherir a un criterio restrictivo de interpretación. ${ }^{32}$ Complementa lo precedente Gracia Martín, ${ }^{33}$ quien aduce que para que pueda ser decomisado el objeto material en los casos en que sea de propiedad del autor, es preciso que se adicione una regulación específica que exceptúe la regla general (v. gr. artículo $374 \mathrm{CPE})$.

En oposición a lo precedente, existió una doctrina que postulaba un concepto amplio de efectos. Así, Groizard para el código de 1870 y Ferrer para el código de $1944,{ }^{34}$ entendían que están comprendidos en estos "los objetos que forman parte del delito y los producidos por el mismo", "siendo apartados de esta categoría solo aquellos que pertenezcan a un tercero irresponsable. Peris/Plá, para

\footnotetext{
28 FERNÁNDEZ (2000), p. 952.

${ }^{29}$ Ibid.

${ }^{30}$ CÓRDOBA (1976), p. 196.

31 "Al desconocerse quién es el propietario del dinero decomisado en la sentencia, la conclusión no puede ser otra que reputar dueño del mismo al poseedor, con apoyo en el artículo 635.4 de la Ley de Enjuiciamiento Criminal (STS 46/98, 20-1)", en: CLIMENT (2011), p. 652.

32 Guinarte (1996), p. 659.

33 GRACIA (2004), p. 502.

${ }^{34}$ FERRER (1947), pp. 229-230.

35 GroizARD (1872), p. 308.
} 
el código de 1995, adhieren a esta comprensión amplia del término, esgrimiendo que es la concepción que es más fiel a la interpretación teleológica del artículo 127 CP "cuya finalidad es la privación al delincuente de cualquier ventaja obtenida del delito". ${ }^{36}$ Conde-Pumpido, finalmente, para la regla posterior a la LO 15/2003, extiende aún más este concepto, señalando que comprende cualquier cosa material sobre la que recayere la acción delictiva.

En cuanto a los instrumentos, son aquellos bienes con que se haya preparado o ejecutado un delito doloso o imprudente o una falta, si y solo si hubieren sido utilizados o se encuentran relacionados con las acciones a las que son imputables (causalmente) la preparación o comisión del delito (relación de medio a fin). Cierta jurisprudencia agrega, a su vez, el requisito de utilización próxima en el tiempo.

Hasta antes de la entrada en vigencia de las sucesivas reformas a la regulación del comiso, existían diversas interpretaciones en cuanto a su alcance. Muy peculiares resultaban las de Groizard y Córdoba Roda a los códigos de 1870 y 1973, respectivamente, por ser iconoclastas -en su época- que hoy gozan de plena vigencia. El primero, en virtud de que lo hacía extensivo a los actos preparatorios punibles. ${ }^{37}$

Ahora bien, no obstante que la doctrina posterior a la LO 15/2003 se encuentra conteste en la inclusión de los objetos que posean una relación de medio a fin con la preparación del injusto (aduciendo fundamentalmente la peligrosidad objetiva de dichos instrumentos) no existe uniformidad en esta respecto a qué actos preparatorios permiten la imposición del comiso. Gracia Martín postulaba que solo procedía cuando se efectuaban actos preparatorios punibles en virtud de que el comiso precisa de la imposición de una pena y "en los casos que se permite su imposición en ausencia de pena, el hecho debe ser al menos punible". 38 Puente, en cambio, incluía el decomiso de los bienes empleados en un acto preparatorio aunque no fuere este punible, basándose en el -a su juicio- fundamento justificador de la institución (peligrosidad objetiva de los bienes), que es, a la vez, el límite, junto al principio de proporcionalidad, a la imposición del comiso. Llega a una conclusión similar, mas mediante una interpretación gramatical, Ramón Ribas. Es menester destacar que no obstante los beneficios político-criminales de la interpretación de estos dos últimos autores, conforme a la evolución del derecho positivo español implica la afirmación de que esta consecuencia jurídica es una excepción carente de consagración positiva a la modificación adoptada por el Código Penal de 1995, que establece como máxima la no punición con carácter general de ningún acto preparatorio, es decir, la restricción tanto de los actos

\footnotetext{
36 PERIS/Plà (2000), p. 952.

${ }^{37}$ GroizARD (1872), pp. 308-309.

38 GraCia (2006), p. 567.
} 
preparatorios punibles como de aquellos tipos de la Parte Especial sobre los cuales pueden estos aplicarse.

En lo que sí existe acuerdo es en la necesidad de que dichos instrumentos hayan sido utilizados para la preparación y/o ejecución del delito, no bastando con que hayan estado destinados a la realización del delito concreto. Así Aguado $^{39}$ y Puente. Pareciere, sin embargo, que dicha regulación aún es perfectible. Al exigirse la utilización material de dichos medios, en el caso de que alguien ingrese a un domicilio particular y perpetre un robo con fuerza, si es que este iba armado ante la eventualidad de encontrar a alguien en su interior, al no utilizar en forma alguna dicha arma, esta no le podría ser decomisada. Actualmente, dispone de una redacción similar el StGB, el que al añadir la locución "o hayan sido destinados a tal fin", permite ampliar el campo de acción del comiso español. Ante las posibles réplicas que pueden surgir sobre cuál es el límite a la imposición de esta figura, si se tiene a la vista que prácticamente cualquier cosa puede ser utilizada para ejecutar la coacción mediante violencia (v. gr. caso lederriemenfall, BGH, 1955) o para preparar el delito, es que el StGB utiliza una expresión unívoca: "Bestimmt", lo que determina la exigencia de que dichos instrumentos con certeza hubieren o podrían bajo determinados supuestos esperables haber sido utilizados. Muy similar a esta última regulación es la establecida por la ley 20.000 chilena. $^{40}$

Córdoba Roda, a su vez, se empeñó en demostrar que el comiso de instrumentos, en el código de 1973, procedía respecto de toda clase de delitos y no únicamente para los dolosos, en virtud de que si bien la voz instrumentos denota una relación de medio a fin, el artículo $48 \mathrm{CPE}$ (actual 127) "no refiere, en absoluto, tal preordenación a un resultado típico, sino [...] a la ejecución del delito" ${ }^{41}$ (voluntad de acción de la teoría finalista). Dicho argumento, con la exigencia positiva expresa de dolo del Código Penal de 1995, quedó totalmente obsoleto. Aun así, pervivían voces críticas, fundamentalmente en atención al contenido de injusto personal de la conducta. ${ }^{42}$ Tras la LO 5/2010 esta discusión se encuentra zanjada, ello en virtud de que el artículo $127 \mathrm{~N}^{\circ} 2 \mathrm{CPE}$ faculta expresamente al tribunal a aplicarlo en los casos de comisión de delitos imprudentes ${ }^{43}$ en los que la ley prevea la imposición de una pena privativa de libertad superior a un año.

\footnotetext{
39 AgUAdo (2003), pp. 3-4.

40 Artículo 45: “[...] todo otro instrumento, que haya servido o bubiere estado destinado a la comisión [...]".

${ }^{41}$ CÓRDOBA (1976), p. 197.

42 "-[C]ontra la seguridad vial, contra el ambiente, por ejemplo- que pueden reducirse a ambiciones económicas o al placer de la velocidad despreciando los terribles e irreversibles males que con su conducta pueden ocasionar". QUINTERO (2010), p. 7.

43 Reforma que hace de esta regulación algo más armónico, ya que no limita la exacción de las ganancias ilícitamente obtenidas según los elementos subjetivos del tipo concurrentes sino que únicamente a su efectiva concurrencia.
} 


\section{iii) Comiso de ganancias}

Fue señalado por primera vez de forma explícita en la LO 1/1988 para los delitos de tráfico de estupefacientes (artículo 344 bis e) CPE) e incorporado expresamente con carácter general por el Código Penal de 1995. Bajo la regla original, solo podían ser decomisados aquellos beneficios sobre los cuales se probare fehacientemente que derivaban del hecho delictivo objeto de la investigación, excluyéndose su aplicación, por tanto, respecto de aquellos que no se demostrare una íntima ligazón, ${ }^{44}$ no obstante tener el órgano adjudicador la convicción respecto de su ilícita procedencia (derivando en la impunidad y preservación de riquezas de orígenes inexplicables). Esto, en conjunto a la garantía legitimatoria de proporcionalidad con el hecho perpetrado, operaba como el límite más usual a la extensión en la aplicación del comiso (sin perjuicio de su utilización para el pago de las penas pecuniarias o para asegurar el cumplimiento de la responsabilidad civil determinada en la sentencia condenatoria).

La LO 5/2010, por las dificultades que acarreaba para la persecución del dinero, suprimió dicha garantía procesal para los casos de "efectos, bienes, instrumentos y ganancias procedentes de actividades delictivas cometidas en el marco de una organización o grupo criminal o terrorista, o de un delito de terrorismo". Es decir, esta reforma incorporó una presunción legal (inversión de la carga de la prueba) que determina como proveniente del delito el patrimonio cuando sea desproporcionado en relación con los ingresos legalmente obtenidos (por lo que "inexplicable" y "delictivo" se transforman en conceptos legalmente idénticos), deviniendo en indiferente, por tanto, las acciones concretas (participación) del sujeto pasivo de la consecuencia accesoria, siendo lo único relevante "la suma de las ideas de pertenencia a la organización y tenencia de bienes" 45 en caso de que exceda su capacidad económica visible (fundamento y límite de la misma). ${ }^{46}$

No obstante lo anterior, esta reforma no está exenta de deficiencias, ya que excluye la imposición del comiso para aquellos sujetos que no pertenezcan a una organización delictiva (a pesar de la comisión de un delito continuado). Asimismo, porque en los casos en que el sujeto sobre quien se impone el comiso adolece de toda fuente de ingreso lícita, esta consecuencia accesoria devendría indefectiblemente en una confiscación. A su vez, como señala Quintero Olivares,

44 STS 2.a 20.9.02, en GARBERÍ (2006), p. 775.

45 Ibid., p. 5.

46 "Los citados preceptos excluyen del comiso aquellos efectos, instrumentos o bienes que pertenezcan a un tercero de buena fe no responsable del delito, y en el presente supuesto, aun cuando formalmente el dinero parezca ser en parte también de la propiedad de la esposa (sic) del recurrente pues así consta administrativamente, la realidad de las cosas demuestra lo contrario, esto es, que es fruto o ganancia del tráfico de drogas pues no esta (sic) justificado por la pretendida operación inmobiliaria o por negocios de la hostelería, razón por la que se comprende y comparte la decisión del Juzgador de instancia de decretar su comiso y que queda reflejada en el Fundamento de Derecho". SAP Málaga 8a 15.05.03. GARBERí (2006), p. 781. 
se enfrenta a la dificultad de probar la ausencia de buena fe en caso de que el bien conste a nombre de un tercero (aunque los disfrute el sujeto pasivo del comiso). En razón de ello, propone este autor, que no se está de buena fe "cuando se trate de bienes en poder de personas jurídicas que el responsable controle, o de parientes o amigos suyos". ${ }^{47}$ Así pareciera haberlo entendido también la jurisprudencia. ${ }^{48}$ Gracia Martín, a su vez, considera inexistente la buena fe no solo cuando el tercero obtuvo las ganancias con conocimiento de su origen delictivo, sino que también cuando "previó o debía haber previsto la posibilidad del origen delictivo" 49 (postura que, por la diversidad de sus presupuestos, es complementaria con la de Quintero Olivares).

La regulación del comiso de ganancias, señala cierta doctrina (contrariando la naturaleza jurídica de esta consecuencia accesoria), a diferencia del \ 73 (2) oración primera StGB, soslaya cualquier referencia al decomiso de los bienes obtenidos con la inversión, utilización o explotación de las ganancias ilícitas ${ }^{50}$ (v. gr. renta obtenida de casa usurpada, intereses bancarios de dinero hurtado). Vizueta señala que en razón de ello es que se ven excluidas del comiso de ganancias, "pues ni son ganancias provenientes, en sentido estricto, de la infracción penal, sino más bien de actuaciones posteriores a esta [...] ni constituyen transformaciones de una ganancia ilícita, pues no sustituyen u ocupan el lugar de esta, sino más bien la incrementan". ${ }^{51}$

En cuanto al momento en que se entienden obtenidos los beneficios, no existe disensión en la doctrina. Como es un proceso real-afirma Bacigalupo Saggese- "este no puede depender de la forma o eficacia del negocio jurídico que da lugar a la posterior obtención del beneficio" 52 (el beneficio se entiende radicado en el instante en que el autor puede valerse de él [económicamente], deviniendo, por tanto, en innecesario "el cobro del cheque"). Como consecuencia de ello, no se encuentran comprendidas dentro de las ganancias obtenidas aquellas ganancias futuras que posean el carácter de eventuales.

Si bien no existe regulación positiva que determine si el comiso ha de recaer sobre las ganancias brutas (sin descontar los gastos realizados por el sujeto pasivo del comiso para la obtención de estas) o sobre las ganancias líquidas obtenidas con la realización del injusto (como el StGB hasta el 7 de marzo de

${ }^{47}$ QUINTERO (2010), p. 7.

48 "Las reclamaciones presentadas por sociedades que dicen ser titulares de los bienes decomisados permiten aplicar la teoría del levantamiento del velo cuando de la realidad procesal y de las pruebas practicadas se desprenda claramente que la titularidad de las fincas es un mero decorado que se utiliza para presentar una realidad que no se corresponde con la verdadera situación de los bienes". STS 867/02, 29-7, en CLIMENT (2010), p. 653.

49 GRACIA (2006), p. 570.

50 ViZUETA (2007), p. 165.

${ }^{51}$ Ibid., p. 166.

${ }^{52}$ Bacigalupo (2002), p. 7. 
1992), la jurisprudencia y cierto sector de la doctrina ${ }^{53}$ parecieren haber optado por la primera solución (idéntica a la adoptada por la AWG/STGBÄG). En oposición a esto, ilustra Faraldo, perviven quienes adhieren al principio de ganancias netas, en razón de su naturaleza jurídica (repudio al enriquecimiento ilícito originado en el injusto) como también por una interpretación literal del término "ganancias". 54

Finalmente, no obstante que recién con la entrada en vigencia del Código Penal de 1995 se incluyó de forma expresa la regulación genérica del comiso de ganancias, fue este decretado con anterioridad de forma sistemática por los tribunales. ${ }^{55-56}$ En doctrina, tenía idéntico entendimiento, Puig Peña. ${ }^{57}$ Se oponían a dicha interpretación, a su vez, Manzanares/Albácar. ${ }^{58}$

Ahora bien, dentro del comiso de ganancias se comprende el comiso del valor equivalente (comiso impropio), el cual se introdujo recién con la reforma de la LO 15/2003. Su particularidad es que permite, en los casos en que fuere imposible el decomiso de las ganancias provenientes del injusto, decretarlo sobre otros bienes de valor equivalente que pertenezcan al sujeto pasivo de la consecuencia accesoria (no obstante su mayor amplitud, similar al $\int 74 \mathrm{c}$. StGB). ${ }^{59}$ Esto posibilita dar una solución idónea a los casos en que los bienes ya no se encuentran a disposición de este último (por destrucción, ocultación, adquisición lícita por un tercero de buena fe, etc.). Sin embargo, esta institución no se encuentra exenta de críticas. Esgrime Valero que al no establecer la ley un ligamen directo entre los bienes decomisados y el producto de la actividad ilícita, es decir, que al proceder este sobre cosas adquiridas lícitamente que no tienen relación alguna con el delito, el comiso constituye un acto de confiscación. Señala que este concepto es constitucionalmente inocuo solo cuando se entiende por bienes equivalentes a aquellos "bienes y valores que, sin ser producto directo o indirecto de la conducta ilícita, o estar vinculado a la misma por haber sido utilizados como medio o instrumento, sí han sido empleados para mezclar, encubrir o tratar de ocultar aquellos, o fueron adquiridos con el producto de la venta de los haberes espuriamente conseguidos". ${ }^{60}$ Sin embargo, aun cuando se realizare ello, evidencia Aguado, ${ }^{61}$ existe otra falencia en su regulación: la

53 Así, por ejemplo: AgUAdo (2000), pp. 101-102.

54 "Si de esta [conducta antijurídica] se ha obtenido 100, pero el coste para su obtención ha sido también 100, el enriquecimiento patrimonial es cero". VIZUETA (2007), p. 171.

55 RAMÓN (2004), p. 524.

56 STS, 30 de octubre de 1973. Sentencia transcrita en: MANZANARES/ALBÁCAR (1990), p. 342.

57 PUIG (1952), pp. 456-457.

58 "En cuanto a los objetos provenientes de la infracción, su identificación con los productos sceleris, o producidos por el delito, excluye los sceleris quaesitae, los objetos de la infracción, el frutus sceleris conseguido a través del producto originario, los medios de prueba como tales, y la ventaja patrimonial lograda". MANZANARES/ALBÁCAR (1990), p. 339 y MANZANARES (1984), pp. 6-7.

59 Este último exige que el sujeto pasivo del comiso haya frustrado la ejecución de este mediante cualquier medio que impida su aplicación (v. gr. destrucción, consumo).

${ }^{60}$ VALERO (2009), p. 85.

${ }^{61}$ AgUAdo (2003), pp. 6-7. 
inexistencia de una regla positiva de determinación de la cuantía de los bienes en caso de imposición de comiso por sustitución. Esboza para ello, no obstante, dos posibles soluciones: o una demostración fehaciente [irrefutable] del valor de dichos bienes o la suficiencia de una mera estimación del tribunal para su fijación. Defiende esta la segunda tesis aduciendo factores de carácter económicos (solución coincidente con el $\int 73 \mathrm{~b}$. StGB). ${ }^{62}$ Avala esta toma de postura el hecho de que esta solución permite adecuar la disminución del valor (v. gr. desgaste por uso, obsolescencia), así como las ganancias estimadas (v. gr. interés corriente). No obstante lo precedente, esta solución podría problematizarse. Por ejemplo: ego usurpa la casa de alter. Luego, la arrienda a un precio muy inferior al valor que el mercado fija para inmuebles de semejante tamaño y ubicación. Entonces, la pregunta que cabe realizarse es si el valor equivalente a los beneficios obtenidos ¿debe corresponder solo al valor del bien menos su depreciación, más las ganancias efectivamente obtenidas? o, ¿también a esta ecuación debería adicionársele las ganancias que debieron ser adquiridas? La respuesta, si se considera la finalidad civil del comiso de ganancias (repudio al enriquecimiento sin causa), implica la restitución de lo que debería haberse obtenido y no acaeció (empobrecimiento por la imposibilidad de desarrollar libremente una actividad lucrativa), haciéndose cargo así el sujeto pasivo de la "pérdida de la oportunidad" (posibilidad fáctica de aprovechamiento) sufrida por la víctima (en el ejemplo, restituye no solo el valor de las rentas obtenidas de la casa, sino que también el saldo no cobrado hasta alcanzar el precio de mercado). Asimismo, debería incluirse dentro de los beneficios que se ha irrogado el autor todos aquellos gastos que haya ahorrado con la realización del injusto. ${ }^{63}$

No obstante que será analizado posteriormente, difiero de la postura de Valero, pues, no es necesario un ligamen absoluto entre la cosa y el hecho (vinculación directa entre los objetos decomisados [=ganancias] e injusto), siendo suficiente uno entre el provecho y el hecho. Deviene en irrelevante, por tanto, el objeto particular decomisado, ya que la imposición del comiso de ganancias no obedece a la peligrosidad de la cosa, sino que al enriquecimiento injustamente adquirido, el cual sí es consecuencia directa de la comisión del ilícito.

Finalmente, es menester destacar la sagaz precisión de Gracia Martín: como el artículo $127 \mathrm{~N}^{\circ} 3 \mathrm{CPE}$ solo permite imponer el comiso por el valor equivalente sobre cosas que "pertenezcan a los criminalmente responsables del hecho", este "no podrá aplicarse cuando las ganancias no han sido

\footnotetext{
62 \$73b. StGB: "El volumen de lo logrado y de su valor así como la magnitud de la pretensión cuyo cumplimiento sustraería al autor o partícipe de lo logrado en el hecho, puede ser avaluado".

${ }^{63}$ En el ejemplo de la usurpación, el pago de la renta de la casa por el tiempo que la ocupó. La naturaleza de esta figura hace que ello tenga como límite el enriquecimiento sin causa de la víctima (renta correspondiente al autor de la usurpación más beneficios obtenidos por este producto de las rentas percibidas).
} 
obtenidas nunca por los responsables porque las mismas han afluido directamente de un tercero". ${ }^{64}$

\section{iv) Límites legales y doctrinarios a la imposición del comiso}

(iv.1) Un bien por el hecho de calificar como efecto o instrumento no queda, en la praxis judicial, indefectiblemente sujeto a ser decomisado si concurren todos los presupuestos sistemáticos que establece la ley para su imposición. Así lo ha entendido un sector de la doctrina que restringe su aplicación mediante una interpretación teleológica del artículo 127 CPE (prevención especial objetiva). En efecto, Gracia Martín promueve "dejar de aplicarlo siempre que la cosa no sea peligrosa [juicio de peligrosidad objetiva] y no se compruebe la probabilidad de que sea utilizada en el futuro para la comisión de nuevos hechos antijurídicos". ${ }^{65}$ Ramón Ribas comparte esta postura, precisando que ello únicamente es posible si se admite que el juicio abstractamente realizado por el legislador, quien considera, en principio, objetivamente peligroso todo bien empleado u originado en la preparación y ejecución de un delito es necesario mas no suficiente, precisándose de la realización de un nuevo juicio de peligrosidad objetiva, esta vez por el adjudicador, para poder determinar su efectiva imposición. ${ }^{66}$ Así también, Puente, quien no obstante añade un tercer requisito para la aplicación del comiso: que el objeto constituya un elemento esencial en la comisión del delito ${ }^{67}$ (requisito presumiblemente no adicionado por Gracia Martín por entender que ello es consecuencia lógica del principio de proporcionalidad, establecido en el artículo $128 \mathrm{CPE})$.

Córdoba Roda ${ }^{68}$ denunciaba, en su época, una práctica jurisprudencial similar en el resultado. Señalaba que solo eran decomisadas aquellas cosas que de forma más característica integraban los efectos o instrumentos (v. gr. armas en atentados contra las personas) y no todo objeto constitutivo, en los hechos, de efecto o instrumento, sin mediar un sopesamiento previo de su importancia para la acción ejecutada por el tribunal.

(iv.2) Un segundo límite lo constituyen los casos en que el titular de la cosa sea un tercero de buena $\mathrm{fe}^{69}$ no responsable del delito, que haya adquirido los bienes legalmente.

64 Gracia (2006), p. 573.

65 Ibid., pp. 563-564.

${ }^{66}$ Tratado más extensamente en: RAMÓN (2004), pp. 780-782.

67 Así también la jurisprudencia: "La posesión física de la droga no convierte sin más en instrumento del delito el uso que del vehiculo pueda hacer en cualquier momento el acusado, pues la droga puedo (sic) haberse transportado de cualquier otro modo, incluso sin ningún vehiculo [STS 314/07, 25-4]”, en: CLIMENT (2011), p. 657.

68 CÓRDOBA (1976), pp. 197-198.

69 "Como la esposa del acusado no fue coacusada, no se podía decretar el comiso de los vehiculos pertenecientes a la misma, porque tiene la condición de tercero no responsable de la infracción penal [STC 92/97, 8-5]" en: Climent (2011), p. 653. 
Durante la vigencia del Código Penal de 1973 era suficiente que la cosa perteneciera a un tercero no responsable del delito, lo que lo amparaba del comiso incluso cuando los hubiera adquirido de mala fe. Ello era consecuencia inmediata de la naturaleza jurídica de pena de esta figura. Sin embargo, a partir de la entrada en vigencia del Código Penal de 1995 se adicionaron dos nuevas condiciones para poder sortear la imposición del comiso, coexistiendo, no obstante, diversos entendimientos al respecto. Gracia Martín interpreta a la buena fe como la capacidad de garantizar el cumplimiento por el propietario de su deber de vigilancia de la cosa a fin de evitar su utilización en el futuro para la comisión de nuevos hechos delictivos. Aguado en cambio niega la buena fe cuando quien adquiere la cosa no tiene la "necesaria creencia" (prueba negativa) de que quien transfiere es el dueño: "conociendo su origen ilícito y su carácter decomisable". ${ }^{70}$ Descarta también, esta autora, la buena fe en caso de facilitación imprudente de instrumentos para la comisión de delitos. Mapelli, a su vez, acota la concepción de Aguado, ya que estima que no concurre buena fe solo cuando el sujeto conoce directamente que la cosa ha sido instrumento, efecto o ganancia del delito (prueba positiva). Es preciso señalar que cuando el tercero conoce el origen delictivo del bien, no solo no se encuentra de buena fe, sino que además podría constituirse como autor de delito de receptación (encubridor para la legislación chilena), en que el tercero [aparente/simulado] del injusto primigenio es asimismo autor de un delito distinto (encubrimiento del origen ilícito mediante transformación).

En lo que sí existe concierto en dogmática es que la locución "tercero no responsable" se realiza en oposición a los conceptos de autor y partícipe..$^{71-72}$

A su vez, en cuanto a la expresión "adquisición legal", acaece, conforme a la doctrina mayoritaria, no [solo] cuando la cosa sea legítima o irreivindicable, sino que basta que su adquisición sea administrativa y penalmente lícita [estándar ostensiblemente menos exigente]. Además, la ilicitud, conforme a las reglas generales y a la garantía legitimatoria de culpabilidad (procesal), debe ser probada por el ente persecutor. En relación con lo anterior, es importante elucidar como conviven los requisitos de buena fe y adquisición legal, realzando el que la sola titularidad administrativa de una cosa no convierte a su dueño en tercero de buena

\footnotetext{
70 Aguado (2000), p. 48.

${ }^{71}$ Contrario a esta postura [al menos para la sección 141 de la Ley sobre la Administración de la Aduana (1979), Reino Unido] tanto la Comisión Europea de Derechos Humanos (C.E.D.H.) como el Tribunal Europeo de Derechos Humanos (TEDH), para quienes el comiso de instrumenta sceleris posee el carácter de procedimiento civil, estableciéndose, en consecuencia, un proceso in rem para la conculcación de aquellos (deviniendo, ergo, en irrelevante el sobre quién recae la calidad de propietario del bien así como los elementos subjetivos concurrentes [mens rea] en el sujeto pasivo de la acción penal). Caso Air Canadá con el Reino Unido, TEDH, 05 de mayo de 1995. [citado por:] VERVAELE (1998), pp. 68 a 72. Se muestran contrarios a la naturaleza no penal [civil] de los instrumentos los magistrados Martens y Russo (voto disidente).

${ }^{72}$ La jurisprudencia es dispar. Véase STS 2. ${ }^{2}$ 27.6.03, en: GARBERÍ (2006), p. 784. Así también: STS 928/03, 27-6, en: CLIMENT (2011), p. 653.
} 
fe, ya que aquella debe concurrir en conjunto con la ignorancia de los vicios existentes en el título de adquisición al momento en que se consolida el acto jurídico (razón por la que deviene en irrelevante la buena fe sobreviniente). ${ }^{73}$

Finalmente, es menester analizar los casos de titularidad compartida de la cosa, en la que poseen la calidad de copropietarios sujetos pasivos de la acción penal e individuos ajenos [y de buena fe] al hecho delictivo. La jurisprudencia es dispar respecto de su procedencia y, en caso afirmativo, si lo es parcial o total. ${ }^{74}$

(iv.3) Una tercera barrera la constituye el principio de proporcionalidad, consagrado expresamente en el artículo $128 \mathrm{CPE}$, el cual tiene su primer antecedente en la reforma de la LO 8/1983, que lo incorpora en el artículo 48 del código de 1973. Esta disposición consagra dos límites a la imposición preceptiva del comiso: el principio de proporcionalidad en sentido estricto, y el de satisfacción previa de responsabilidades civiles.

Una regla imperativa de imposición de comiso ("[t] oda pena que se imponga por $[\ldots]$ ") sería incompatible con el principio de proporcionalidad (tanto ordinal como cardinal), por cuanto no toda medida de culpabilidad es apta para abarcar la extensión de la sanción de comiso. Sería discordante, asimismo, con la interpretación teleológica del artículo 127 CPE.

Lo primero que debe tenerse en consideración es el carácter especial de esta regla, ya que si bien el principio de proporcionalidad forma parte del catálogo de derechos fundamentales, se encuentra establecido en la presente disposición únicamente para los efectos e instrumentos del delito [no peligrosos] (lo que reafirma, una vez más, su naturaleza jurídica diversa respecto del comiso de ganancias). Ahora, si bien intuitivamente es razonable afirmar que el comiso de ganancias se encuentra amparado, conforme a las reglas generales, por el principio de proporcionalidad, perviven en doctrina disímiles opiniones. En efecto, Cazorla considera que esta garantía legitimatoria no es aplicable a este, ya que lo único determinante es que guarden una relación próxima, probada y justificada con la acción por la que se condena al sujeto, evitando así que se enriquezca por las sucesivas transformaciones que deriven de los beneficios del mismo. En oposición a ello, Mapelli y Aguado incluyen al comiso de ganancias dentro de la esfera de resguardo del principio de proporcionalidad, ello en atención a que la posesión de buena fe no puede ser el único límite a su imposición si se tiene en consideración la dureza injusta para el sujeto pasivo que puede resultar de una aplicación como esta. Es importante, a su vez, tener en consideración que esta facultad de no decretarlo o decretarlo parcialmente viene

73 "La recurrente no adquirió el inmueble en la creencia de la inexistencia en el título de vicio alguno que lo invalide (arts. 433 y 1950 CC), sino que conocía el origen ilícito del dinero empleado para la compra de los bienes, por lo que su condición no es la de tercero respecto de dicha adquisición", en: CLIMENT (2011), p. 654.

${ }^{74}$ STS 450/07, 30-5, en: CLIMENT (2011), p. 654 y STS 2.a 16.12.99, en: GARBERí (2006), p. 778. 
condicionada a que los efectos o instrumentos sean de lícito comercio, condición válidamente criticada por la doctrina quien considera que el criterio determinante debe ser la peligrosidad de los bienes, ello ya que advierte que la licitud no siempre se traduce en ausencia de esta.

Es menester tener claridad respecto de qué circunstancias son tenidas a la vista por el tribunal al momento de efectuar el juicio de ponderación. Por un lado, están sobre quién recae el comiso (autor/partícipes o terceros) así como la naturaleza del bien (suntuario o necesario), y por el otro, el valor de los instrumentos y efectos, así como la naturaleza y gravedad de la infracción ${ }^{75}$. Aguado le concede al término "naturaleza" una vinculación con el bien jurídico protegido, excluyéndose, por tanto, los instrumentos y efectos utilizados/provenientes en/de otros delitos y, aquellos que no obstante poseer dicho vínculo causal no son elementos necesarios para la comisión de un delito tal. ${ }^{76}$

En cuanto a la responsabilidad civil, el menoscabo patrimonial que sufre el condenado con el pago de una indemnización de perjuicios tiene un efecto compensatorio que determina que no obstante que el comiso sea proporcional, no se imponga o se lo haga de forma parcial (conexión heterogénea). En efecto, señala Ramón Ribas que el efecto penal derivado de la satisfacción de la responsabilidad civil se produce porque el comiso es utilizado como instrumento de política civil (favorecimiento y propensión de la justicia correctiva).

Finalmente, es en virtud de este principio que se debate en doctrina el carácter de la sanción de comiso. La doctrina mayoritaria, así como también la jurisprudencia, ${ }^{77}$ lo califican como de imposición potestativa para el adjudicador (si se acredita el cumplimiento de sus presupuestos). En oposición a ello, cierto sector de la doctrina lo califica como imperativo, solamente con el límite de petición expresa por el sujeto activo de la acción y de la interpretación teleológica. Esto último en base al encabezado del artículo $127 \mathrm{~N}^{\circ} 1 \mathrm{CPE}$ ("[ $\left.\mathrm{t}\right]$ oda pena que se imponga por un delito o falta dolosos llevará consigo [...]") que determinaría que el no cumplimiento de lo dispuesto en el artículo $128 \mathrm{CPE}$ sea un presupuesto más para su imposición y que, como tal, debe ser probado en juicio.

(iv.4) Dependiendo de la naturaleza jurídica que se le atribuya (vinculado al ius puniendi, ya sea como tercera clase de sanción penal o como sanción administrativa),

\footnotetext{
75 "Transportada la droga en un vehiculo propiedad de Juan Francisco este se convierte en instrumento de ejecución de la conducta penalmente reprochable y, por tanto, susceptible de ser decomisado, si bien, atendiendo a la desproporción entre su valor y la naturaleza de los hechos el traslado de un paquete de estupefaciente (sic) de 123 gramos de peso, y a que el turismo era empleado por el acusado para sus actividades cotidianas, no apareciendo que su uso exclusivo fuese para transporte de la sustancia intervenida o que hubiese sido expresamente adquirido para tal finalidad, será aplicable la regla del artículo 128 del Código Penal, no siendo procedente acordar el comiso (SAP Baleares 1.a 23.2.98)", en: GARBERÍ (2006), p. 783.

76 AguAdo (2000), p. 57.

77 STS 314/07, 25-4 y STS 154/08, 8-4, en: CLIMENT (2011), p. 652.
} 
el comiso se encuentra sujeto, entre otros a los principios de legalidad, acusatorio y de contradicción. ${ }^{78}$ No así al principio de presunción de inocencia.

\section{v) Presupuestos del comiso: ¿tipicidad o ilicitud?}

Su regulación excluye la exigencia de culpabilidad. De hecho, ni siquiera supone responsabilidad personal. Sin embargo, no está determinado si el comiso precisa de la concurrencia del tipo global de injusto o basta simplemente con que la acción sea típica. Una aplicación irrestricta del comiso, conforme a la vigente reducción positiva de los elementos de la teoría del delito necesarios para su imposición ("aun cuando no se imponga pena a alguna persona por estar exenta de responsabilidad criminal o por haberse esta extinguido, en este último caso, siempre que quede demostrada la situación patrimonial ilícita") puede derivar, por ejemplo, en el caso del uso de armas por la autoridad dentro del ejercicio legítimo de su cargo, en la supresión material de las fuerzas de orden y seguridad pública como consecuencia del decomiso de cada arma usada durante la coacción pública directa. Igualmente, se afectaría el derecho de propiedad [privada] en el caso de la legítima defensa, ya que si esta no exige acreditar el origen del medio que se utilizó para repeler la violencia no existe motivo para decomisar dicho instrumento, sancionando con la disminución de su patrimonio a quien es víctima de la agresión inicial (por una actuación jurídicamente autorizada).

El párrafo $4^{\circ}$ del artículo $127 \mathrm{CPE}$, por tanto, rebaja el estándar de imposición del comiso desde un hecho típico, antijurídico y culpable [o no] a solamente típico. Lo innecesario de la culpabilidad está fuera de discusión, mas la necesidad de la antijuricidad es manifiesta, por cuanto si no se desnaturalizaría al comiso, no respondiendo ya a una peligrosidad prospectiva del bien, sino que a la realización pretérita de un hecho típico (lo que, además de provocar una desmesurada extensión de esta figura, generaría un colapso en la administración de justicia). ${ }^{79}$

\section{b) Derecho penal alemán}

i) Para un adecuado examen de la regulación general de las sanciones de comiso de ganancias y decomiso en el derecho penal alemán, es preciso efectuar un análisis sobre cuatro momentos temporales diversos:

(i.1) Vigencia del RStrG de 1871: en este, el comiso de ganancias carecía de una cláusula de aplicación general, siendo regulado únicamente de forma aislada en

78 "Por su especial naturaleza, el comiso ba de ser sometido a debate por la acusación en cada caso concreto, sin que baste con la genérica petición de penas accesorias, y solo puede ser impuesto en sentencia para acatamiento de la garantía derivada del principio de legalidad (STS 774/97, 30-5; 398/99, 11-3)", en: CLIMENT (2011), p. 656.

${ }^{79}$ En términos similares: AGUADO (2003), pp. 7-8. 
ciertas disposiciones de la Parte Especial, la que en algunos tipos disponía su imposición de forma preceptiva ( $(335 \mathrm{RStrG}$ ) y en otros de forma potestativa.

Señalaba Maurach que el comiso de ganancias tenía siempre la naturaleza jurídica de pena accesoria, basando ello en que solo podía imponerse a un sujeto culpable $-\mathrm{y}$ no respecto de terceros- ${ }^{80}$ Asimismo, definía este como el "secuestro, por el Estado, de la recompensa del autor (dineros, cosas, cuentas, garantías, etc.) o de su equivalente". ${ }^{11}$ Es decir, el condenado debía restituir la cosa en especie, mas, si ello devenía en imposible, dicha obligación de restitución mutaba en una obligación de pago, la cual debía ser ejecutada según las prescripciones de las penas patrimoniales (no procede la aplicación de una pena privativa de libertad sustitutiva). ${ }^{82}$

A su vez, en cuanto al decomiso, era encuadrado por algunos junto a la indemnización ( $\iint 188$ y 231 RStrG) dentro de los "efectos accesorios" ( $\int 61$ RStrG), expresión que debe entenderse, en sentido negativo, como todo aquello que no son penas ni medidas en sentido amplio. De esta sanción se ocupaban los $\iint 40,41$ y 42 RStrG. Si bien se encontraba regulado de forma general como de imposición facultativa (limitada por el principio de proporcionalidad), muchas veces tenía el carácter de obligatorio (\$S 152, 295, 296a., 335 y 369 RStrG).

En el concepto de decomiso se incluían dos sanciones totalmente diversas: el decomiso regulado con carácter general para todos los hechos punibles dolosos en que el objeto a decomisar se encuentra en propiedad [exclusiva] del autor (comiso "relativamente eficaz") y el comiso regulado en ciertos preceptos de la Parte Especial (v. gr. en los $\iint$ 86, 98, 152, 245a., 284, 295 y 296 RStrG), cuya imposición no se veía limitada según sobre quién recaía su propiedad (comiso "absolutamente eficaz"). Se diferencia este de aquel, a su vez, en que extiende el ámbito de aplicación de los intrumenta sceleris también a aquellos objetos destinados a la comisión del hecho no empleados en su ejecución. Asimismo, en que en ciertos casos contempla la indemnización del propietario y que no precisa de la punibilidad del autor (se impone aun en caso de absolución [en atención a su función preventiva]). ${ }^{83}$

Maurach calificaba al primero como pena accesoria. Consideraba al segundo, a su vez, como una medida preventiva desprovista de carácter penal. ${ }^{84}$ Así también, Mezger ${ }^{85}$ y Merkel. $^{86}$

\footnotetext{
80 MAURACH (1962), p. 520.

${ }^{81}$ Ibid.

82 Ibid.

83 Ibid. p. 524.

${ }^{84}$ Ibid., pp. 522-523.

${ }^{85}$ MEZGER (1958), p. 358.

${ }^{86}$ MerkeL (2004), p. 234.
} 
Disponía de una regla especial, a su vez, el $\int 42$ RStrG, el cual consagraba un decomiso como sanción independiente de la condena del autor, con carácter sustantivo, denominado «procedimiento objetivo», el que precisaba de la concurrencia copulativa de dos condiciones: "[q]ue en la sentencia judicial se afirme como cosa probada la existencia de los elementos constitutivos de alguno de los hechos caracterizados en los $\iint 40$ y 41 RStrG" ${ }^{87}$ y "[q]ue la misma sentencia judicial asegure ser imposible perseguir o condenar a ninguna determinada persona. Esta imposibilidad puede fundarse en obstáculos de hecho (muerte, fuga del culpable, etc.), o en la prescripción del delito mas no [en] la falta de querella tratándose de delitos solo perseguibles a instancia de parte". ${ }^{88}$

Finalmente, es importante destacar que era debatido, en el comiso «relativamente eficaz», si en el caso de enajenación onerosa del objeto del delito, era extensible al producto de la misma. ${ }^{89}$ Señalaba Merkel que se permitía solo por excepción, conforme al $₫ 335$ RStrG.

(i.2) Dictación y entrada en vigencia de la EGOWiG (1968): con esta reforma pasaron a ser posible objeto de decomiso no solo las cosas corporales, sino que también los derechos; determinó la inclusión dentro de los instrumenta sceleris de los objetos utilizados en la huida y en el ocultamiento del botín (etapa de agotamiento del delito); modificó la naturaleza jurídica del decomiso, el que pasó en parte a ser una pena ( $\left(\$ 0\right.$ II 1 ), en parte una medida de seguridad ( $\int 40$ II) y en parte tenía un doble carácter (especialmente al concurrir el $\int 40$ II 1 y 2 ). ${ }^{90}$

Señalaba Welzel que el comiso del valor equivalente se encontraba previsto con carácter general en el $\int 40$ c. RStrG para cuando un partícipe en el hecho que era propietario del objeto al tiempo del hecho, antes de la resolución que impusiere el comiso se aprovechaba de él o lo gravaba con derechos de terceros o de cualquier otro modo obstaculiza el comiso.

(i.3) Dictación y entrada en vigencia del StGB (1975): en este, el comiso de ganancias y el decomiso son calificados por el $\int 11 \mathrm{~N}^{\circ} 8 \mathrm{StGB}$ como medidas, lo que materialmente determina que bajo ningún respecto son penas accesorias ni medidas de seguridad. ${ }^{91}$

El comiso de ganancias (=provechos ilícitos) se transforma desde una sanción especial contenida en ciertos preceptos de la Parte Especial en un instituto jurídico de carácter general (el \15 EGStGB derogó todos los preceptos de la Parte Especial y de las leyes especiales que ordenaban o permitían la imposición

${ }^{87}$ Ibid., p. 235.

${ }^{88}$ Ibíd.

${ }^{89}$ MAURACH (1962), p. 524.

${ }^{90}$ WeLZel (1976), pp. 349-350.

${ }^{91}$ JeSCHECK (1981), pp. 1098-1099. 
del comiso de ganancias). ${ }^{92}$ Ya no precisa, a su vez, de la concurrencia de culpabilidad, bastando para su imposición únicamente la antijuricidad del hecho $(\mathbb{S}$ 11 (1) $\left.\mathrm{N}^{\circ} 5 \mathrm{StGB}\right)^{93}$ que da lugar al provecho patrimonial obtenido ( $\int 73$ (1) StGB). Corresponden a este último, según Jescheck, "no solo cosas y derechos, sino también los provechos derivados del uso y los gastos ahorrados", 94 teniendo por límite a su aplicación -durante este período- la circunscripción a los beneficios obtenidos. Es menester destacar que el hecho punible no es siempre de carácter patrimonial, ello ya que su imposición no atiende a la afectación de un bien jurídico particular, sino que únicamente a una situación patrimonial antijurídica creada "por" el hecho (für die Tat) o "de" el hecho (aus der Tat).

El comiso de ganancias es de imposición obligatoria para las ganancias patrimoniales directamente obtenidas. En cambio, es de imposición potestativa en el caso del comiso de valor equivalente (\$73a. StGB). Además, este puede aplicarse únicamente respecto del autor o partícipes (con excepción de lo establecido en el $\int 73$ (3) y (4) en relación al $\int 14$ StGB). En ciertos casos, no precisa de la adscripción de pena ( $\$ 73 \mathrm{a}$. (3) StGB).

Para la determinación de la naturaleza jurídica del comiso de ganancias, señala Maurach, es menester distinguir el carácter del hecho cometido y la persona que haya obtenido el provecho. ${ }^{95}$ Tiene carácter punitivo cuando se dirige contra el autor que actúa de forma culpable, enriqueciéndose mediante su propio hecho y contra el tercero que ha ofertado la ventaja patrimonial, ya sea para la realización del hecho, o bien teniendo conocimiento de las circunstancias del hecho. ${ }^{96}$ Posee, en cambio, una naturaleza muy próxima al enriquecimiento injustificado civil $^{97}$ cuando el autor no ha actuado de forma culpable o lo ha hecho en lugar de otro, radicándose la ventaja patrimonial en este último. ${ }^{98}$

Por sus implicancias, es preciso resaltar la redacción original del $\int 73^{\mathrm{a}}$.: "[e] $n$ tanto no sea posible el decomiso de un determinado objeto, debido a la naturaleza de lo obtenido o por otra razón, o si se prescinde del comiso de un objeto compensatorio conforme al $\int$ 73 (2), el tribunal impondrá el comiso de ganancias de una suma de dinero que corresponda al valor del provecho obtenido [...]", por cuanto consagra el principio de la ganancia neta,

\footnotetext{
92 MAURACH/GÖSSEL/ZIPF (1995), p. 676.

93 Provecho es toda ventaja patrimonial obtenida como contraprestación del hecho.

94 JESCHECK (1981), p. 1100.

${ }_{95}$ MAURACH/GÖSSEL/ZIPF (1995), p. 677.

96 Ibid.

97 Dispone el \ 812 BGB: "La persona que sin justificación legal obtiene algo de otra persona a expensas de esta, ya sea por transferencia o por otro medio, está obligada a restituir dicho objeto. [...]". A se vez, según el $62 \mathrm{OR}$, a su vez, "[1] a persona que se enriquece de manera injustificada a expensas de otro debe restituir el enriquecimiento. Esta obligación se aplica en particular cuando la persona ha recibido un beneficio sin una razón válida, o por una razón que nunca advino o que, subsecuentemente, dejó de existir". ZWEIGERT/KÖTZ (2002), p. 573.

98 MAuraCH/GÖsSEL/ZIPF (1995), p. 677.
} 
es decir, la deducción de los provechos decomisables de los gastos en que incurría el autor para la realización del hecho.

A su vez, la regulación del decomiso en el StGB (\$S 74 a 76a) se basa en los $\iint 40$ a 42 del RStrG una vez acaecida la EGOWiG de 1968 (quienes la disponían únicamente para cosas pertenecientes al autor culpable). Al igual que el comiso de ganancias, tampoco tiene una naturaleza jurídica unitaria. Señalaba Jescheck que poseía un carácter cuasipenal cuando era impuesto al autor o partícipe a quien pertenecían los objetos al momento de la sentencia (pertenencia jurídica, no económica). Así también, cuando se decomisaban cosas o derechos que correspondían a terceras personas (sin atender a la concurrencia o no de culpabilidad). ${ }^{99}$ En oposición a ello, Maurach destacaba el carácter de pena accesoria/pena patrimonial especificada en relación con el objeto cuando el hecho fuere cometido culpablemente y el objeto pertenece al autor. ${ }^{100}$ Jescheck, por su parte, le atribuía la naturaleza de medida de seguridad cuando se impusiere sin consideración a sobre quien recae la propiedad del bien o sobre la mala procedencia en el caso del comiso de objetos de propiedad de un tercero. Así también, cuando se impusiere para proteger a la comunidad de un peligro. ${ }^{101}$

Si bien Maurach concuerda con Jescheck en cuanto a esta naturaleza jurídica, así como también en los supuestos comprendidos en ella, la identidad no es absoluta. Por ejemplo, establece Maurach que el decomiso tiene el carácter de medida de seguridad cuando se impone sin consideración del carácter culpable del hecho. Para Jescheck, en cambio, en este caso el decomiso tendría una naturaleza cuasipenal. ${ }^{102}$ Maurach, por último, para el caso de una conducta culpable del tercero propietario, señala que corresponde a una medida de compensación cuasicondicional. ${ }^{103}$

Con la entrada en vigencia del StGB, son objeto de decomiso aquellas cosas utilizadas o destinadas a la comisión o preparación de un delito (igual a la regulación del comiso "absolutamente eficaz" del RStrG), ya sea si efectivamente se perpetró, o si el acto preparatorio es autárquicamente punible. Así también las cosas corporales y derechos ( $\$ 74$ (1) StGB utiliza el término “objeto") producidos (exclusión del objeto material de la acción) ${ }^{104}$ por el hecho punible doloso (=dolus malus). El comiso imponible a terceros, finalmente, tiene aplicación bajo presupuestos bastante restrictivos ( $(74 a$. StGB).

99 JESCHECK (1981), pp. 1102-1103.

100 MAURACH/GÖSSEL/ZIPF (1995), pp. 680-681.

101 JESCHECK (1981), p. 1103.

102 MAURACH/GÖSSEL/ZIPF (1995), p. 681.

103 Ibid.

104 Así, tanto JESCHECK (1981), p. 1103; como MAURACH/GÖSSEL/ZIPF (1995), p. 683. 
(i.4) Dictación y entrada en vigencia de la AWG/STGBÄG (1992): ${ }^{105}$ compuesta por la "Ley de Reforma de la Ley de Comercio Exterior, del Código Penal y de otras leyes" y la "Ley de Lucha contra el Tráfico de Drogas y otras formas de criminalidad", determina nuevamente -según cierto sector de la doctrina- la modificación de la naturaleza jurídica del comiso de ganancias, ya que se priva al autor de un provecho mayor del que realmente obtuvo (principio de ganancia bruta sustituye al de ganancia neta), adquiriendo este por tanto el carácter de pena adicional (\$S 73 (1), 73 (3) y 73 b.).

Asimismo, con esta reforma se incorporó el comiso ampliado ( $(73 \mathrm{~d}$. StGB) en el ámbito de la criminalidad organizada, equiparándose el origen "inexplicable" con el "delictivo".

ii) Comiso de ganancias ( $\iint 73$ a 73 e. StGB)

No obstante que Verfall es usualmente traducida como "confiscación de los provechos ilícitos” (así, entre otros, de Vicente, Díaz y García Conlledo, Luzón, Mir, Muñoz Conde y Olmedo; Bofill y Bustos y Yáñez), preferimos la locución "comiso de ganancias", ello en razón de que el término "confiscación" no es aceptable, ya que lo que se entiende por esta corresponde al concepto totalevermögenskonfiscation. ${ }^{106}$ Reafirma lo precedente, a su vez, el Proyecto de Ley (Drucksache) 13/9742 (1998), quien al entender que no existe una distinción conceptual entre Verfall y Einqiehung "propone la supresión en la ley del término «Verfall» y su reemplazo por el de «Einziehung des Erlangten», volviendo a la terminología utilizada antiguamente, sin que por ello se reduzca el ámbito de los posibles beneficios decomisables". ${ }^{107}$ Así también, no obstante no aducir razones, Aguado y Manzanares. ${ }^{108}$

\section{ii.1) Naturaleza jurídica}

Tras la entrada en vigencia de la AWG/STGBÄG, esta sufrió, según cierto sector de la doctrina, una transformación, pues, al consagrar el bruttoprinzip estiman que la $V$ erfall adquiere el carácter de pena adicional, esto al despojar al autor de más de lo que efectivamente ganó con la comisión del hecho. ${ }^{109}$ Sin embargo, advierten Jescheck/Weigend, que esto vulnera el principio de culpabilidad (el $\int 73 \mathrm{StGB}$ solo

\footnotetext{
105 Esta reforma es de importancia sustancial, ya que antes de su entrada en vigencia la utilidad práctica que revestía esta regulación era bastante exigua, ello por un cúmulo de razones, entre otras: la dificultad para localizar las ganancias ilícitas (no obstante que en diversos estados federados de Alemania se persiguen mediante organismos/secciones de recuperación de activos especiales pertenecientes a la policía), la prueba del origen delictivo de dichas ganancias y el cálculo de los gastos en que incurrió el autor. Véase BLANCO (2007), p. 12.

106 ESER (2006), p. 1023.

107 Aguado (2000), p. 150.

108 MANZANARES (1984), p. 4.

109 JESCHECK/WEIGEND (2002), pp. 853-854.
} 
exige la concurrencia de antijuricidad). En virtud de ello plantean para sortear la declaración de inconstitucionalidad la adopción de una solución diferenciada: si el autor actuó de forma culpable se impondrá como pena adicional el provecho bruto obtenido con el delito; si, en cambio, el autor no actuó de forma culpable o la Verfall se impone sobre un tercero que no formó parte del hecho, la pérdida del provecho se limita a los beneficios efectivamente conseguidos (nettoprinzip), perviviendo con ello su carácter de "medida compensatoria cuasi-restitutoria".

No obstante lo anterior, un entendimiento diverso sobre cómo concurren estas figuras podría dar lugar a consecuencias político-criminales más beneficiosas. Es argumentable que la naturaleza jurídica de la Verfall se mantiene inalterada a pesar de su nueva regulación, ello en razón de que lo que Jescheck/Weigend consideran como una privación de una cantidad mayor al enriquecimiento neto obtenido producto de la aplicación del comiso de ganancias es, en realidad, la unión de dos consecuencias jurídicas diversas: Verfall y Einziehung de los instrumenta sceleris. En efecto, señalan dichos autores el siguiente ejemplo:

Un falsificador de moneda invierte 5.000 DM para fabricar billetes falsos que vende por 10.000 DM. Si se declara la confiscación [= comiso de ganancias] de esta última cantidad el autor sufre una pérdida económica global de 15.000 DM; por el contrario, su enriquecimiento neto derivado del hecho babría sido solo de $5.000 D M .^{111}$

Del análisis de este caso, pareciere dable señalar que lo que estos autores no advierten es que acá existe un concurso de sanciones: los 10.000 DM obtenidos son lo único realmente objeto de comiso de ganancias ( $\int 73$ (1) StGB), ya que, aquello invertido para la fabricación de los billetes (5.000 DM) equivale en la praxis a la adquisición de medios (v. gr. una imprenta y tinta) posteriormente utilizados para la confección de los efectos que luego darían lugar al producto objeto del comiso de ganancias, medios que deben, a su vez, ser objeto de decomiso, mas, en este caso, en razón del $\$ 74$ (1) StGB.

\section{ii.2) Regulación común}

Eser divide a la $V$ erfall en tres formas: decretada en contra de los intervinientes en el hecho ( $\$ 73$ (1) StGB); en contra de terceros beneficiados ( $\int 73$ (3) StGB) y en contra de tercero propietario (\$ 73 (4) StGB). Adiciona, asimismo, el comiso ampliado.

Para que el adjudicador pueda decretar la imposición de las tres modalidades de Verfall señaladas, deben concurrir ciertos requisitos [comunes] de procedencia: (i) es condición necesaria y suficiente, la comisión de un hecho

${ }^{110}$ Ibid., p. 854.

111 Ibid. 
antijurídico; (ii) la calificación de un hecho como falta no es óbice para su imposición. Tampoco la de delito imprudente; (iii) los intervinientes deben haber obtenido "por el becho o del becho" "algo" (=provecho patrimonial). Destacan Jescheck/Weigend que estas últimas comprenden las cosas, los derechos, las posibilidades fácticas de aprovechamiento y los desembolsos que el sujeto se ha ahorrado con la realización del hecho. No se exceptúa la imposición de la Verfall cuando los intervinientes ya no dispongan de los beneficios inicialmente obtenidos. Para situaciones como esta, el StGB faculta al adjudicador para imponer el comiso del valor equivalente ( $\int 73 \mathrm{a}$. StGB) o el comiso de los objetos que los intervinientes han adquirido mediante la enajenación del objeto obtenido del hecho, o como compensación por su destrucción, daño o comiso o en razón de un derecho obtenido ( $\$ 73$ (2) oración segunda StGB).

\section{ii.3) Límites legales y doctrinarios al comiso de ganancias}

(1) No podrán decomisarse las ganancias derivadas de un injusto si el ofendido recupera los provechos obtenidos por el autor o partícipe mediante una pretensión civil derivada de la comisión del hecho ( $\int 73$ (1) StGB). En este caso, solo es necesaria la existencia del derecho de restitución o indemnización, no que el ofendido lo ejerza/interponga. ${ }^{112}$ Esta regla consagra el carácter supletorio de la $V$ erfall a las pretensiones civiles, lo que determina que en los delitos económicos y atentados a la propiedad dirigidos contra las personas no puedan recuperarse los provechos delictivos mediante esta figura, reduciéndose ostensiblemente su rango de aplicación. ${ }^{113}$ En razón de lo anterior, no obstante el fundamento de esta institución (impedir el perjuicio para el ofendido mediante una veloz obtención estatal del provecho así como la protección del autor frente a una potencial acumulación de sanciones) es que es necesaria una reforma a esta previsión.

(2) Conforme al $\int 73 c$. (1) StGB, no podrá decretarse la imposición de la Verfall cuando esta suponga un "rigor excesivo" para el afectado (no obstante concurrir sus presupuestos). Con esta regla se compatibiliza el carácter imperativo de la $V$ erfall con el principio de proporcionalidad. Esta norma se ve complementada [para presupuestos diversos], a su vez, por el $\int 430$ StPO, que faculta al tribunal y/o al ministerio público a renunciar a la Verfall y a su tratamiento procesal si esta "carece de importancia al lado de la pena o de la medida o si complica el procedimiento o lo torna muy costoso" ${ }^{114}$ (este último supuesto seguramente vio su aplicación morigerada con la dictación de la AWG/STGBÄG, que redujo sustancialmente la complejidad de la Verfall introducida por la EGOWiG).

112 Ibid., p. 853.

113 Aguado (2000), p. 146.

114 BAUMANN (1986), p. 72. 
(3) El $\int 2 \mathrm{~V}$ StGB dispone expresamente la aplicabilidad de la prohibición de retroactividad tanto a la Verfall como a la Einziehung. ${ }^{115}$

(4) Quienes intervienen en la Verfall tienen el derecho de ser oídos ( 432 StPO) y en general los derechos de que dispone el imputado ( $\$ 433$ StPO). Pueden nombrar un defensor, presentar requerimientos de prueba, tomar parte en el debate e interponer recursos. Adquieren la calidad de sujeto procesal. ${ }^{116}$

\section{ii.4) Alcance del comiso de ganancias: objetos directos e indirectos. Terceros}

La Verfall abarca aquellos provechos directamente obtenidos ("por el hecho o de el becho"), los "frutos" (\$ 73 (2) oración primera) y "sucedáneos" (\$ 73 (2) oración segunda). Según qué forma de estas adopten los provechos ilícitos se determina el carácter de su imposición. Los frutos son de aplicación judicial preceptiva. Los "sucedáneos" (=cosas que sustituyen a las inicialmente decomisables que ya no se encuentran en poder del autor), en cambio, facultativa. Empero, en este último caso, conforme al $\int 73 \mathrm{a}$. StGB, cuando el adjudicador prescinda de su aplicación impondrá el comiso de una suma de dinero que corresponda al valor de lo obtenido.

La Verfall apunta inicialmente al autor o partícipe. Sin embargo, si dichos intervinientes han actuado en lugar de otro ( $\$ 14$ StGB, "acción por cuenta ajena") aquella se impone a este último. Ilustran esto, Maurach/Gössel/Zipf:

\section{El gerente de una sociedad de responsabilidad limitada distrae ciertos objetos de valor pertenecientes a esta, para evitar una ejecución forzosa que la amenaza. ${ }^{117}$}

El gerente sería condenado conforme al \ 14 StGB. La sociedad lo sería, en cambio, por el $\int 73$ (3) StGB (provecho ilícito como ausencia de empobrecimiento).

Puede dirigirse la Verfall, asimismo, contra el tercero dueño o poseedor de la cosa decomisada cuando este haya ofertado la ventaja patrimonial para la comisión del hecho (= recompensa). Igualmente, se impondrá si dicho tercero al ofrecer la cosa tuvo conocimiento de las circunstancias materiales imperantes. Esto no es más que aplicación de las reglas generales si se considera que quien proporciona al autor una cosa (facilitare medios) para que realice un hecho delictivo, según la posición que se adopte, o es cómplice (por no tener dominio funcional del hecho) o coautor (si es coportador de la decisión común al hecho), en virtud de

\footnotetext{
115 ROXIN (1997), p. 163.

116 BAUMANN (1986), p. 215.

117 MAURACH/GÖSSEL/ZiPf (1995), p. 678.
} 
que existe al menos una negligente cooperación para la utilización del objeto (previsibilidad objetiva del comportamiento doloso).

\section{ii.5) Comiso ampliado (erweiterter Verfall, $\$$ 73d. StGB)}

Figura introducida por la AWG/STGBÄG con el propósito de simplificar la exacción de las ganancias derivadas de la criminalidad organizada. Dispone esta el comiso de las ganancias sin exigir previa constatación de que ellas tienen su origen en el hecho antijurídico enjuiciado, siendo condición suficiente para su aplicación la presunción de que tienen un origen delictivo. Es decir, no se impone como consecuencia de la relación de los objetos con una acción, sino que, únicamente en atención a la relación de estos con el autor (Frank), siendo el vínculo con este de carácter negativo al no exigirse que la cosa le pertenezca sino exclusivamente que no sea de propiedad de un tercero. El presupuesto que permite el establecimiento de esta ficción es la inconsistencia entre la cuantía de sus ingresos legales y su patrimonio.

Constituyen requisitos para su imposición [preceptiva] la comisión de un hecho antijurídico vinculado a la esfera de la criminalidad organizada, situación que se determina, al final del día, mediante la remisión expresa del precepto infringido al $\int 73 \mathrm{~d}$. StGB (v. gr. \ 150 (1) StGB) y; que las "circunstancias justifiquen la presunción de que estos objetos han sido adquiridos para la comisión de hechos o de esos hechos" antijurídicos. Esto último determina, a su vez, que es objeto de esta medida cualquier cosa que perteneciere al autor si se encuentra vinculada a ganancias ilícitamente adquiridas, incluidos los bienes compensatorios y las facultades de aprovechamiento.

No obstante lo precedente, perviven en torno a la erweiterter Verfall consistentes críticas respecto de su constitucionalidad. En efecto, Jescheck/Weigend reprochan que su extensión no se limita únicamente a lo que el autor obtuvo producto de la realización de un injusto perteneciente al ámbito de la delincuencia organizada, abarcando su imposición también a aquellos provechos que derivan de cualquier delito, infringiéndose, por tanto, el objetivo por el cual fue legalmente establecido (v. gr. el dinero que el falsificador de monedas obtuvo mediante el agotamiento de un hurto). ${ }^{118}$ Se le imputa también a esta regla la transgresión del principio de culpabilidad, nuevamente por la sumisión al bruttoprinzip. Asimismo, se argumenta que vulnera el principio in dubio pro reo como consecuencia del debilitamiento de las exigencias probatorias del hecho que da lugar a su imposición (argumentación directamente ligada a la anterior). Para esto último, se ha alzado como correctivo [jurisprudencial] la exigencia para su imposición de la "completa convicción judicial" del origen delictivo de los objetos. Si esta no acaece, debe limitarse la erweiterter Verfall al nettoprinzip. ${ }^{119}$ Finalmente, se

118 JESCHECK/WEIGEND (2002), p. 855.

119 Ibid., p. 857. 
alega su contravención al principio acusatorio, en razón de que obliga al imputado a defenderse de hechos no comprendidos en la acusación (la que solamente abarca la comisión del injusto "base"), ${ }^{120}$ extendiendo el tribunal su conocimiento a otros hechos jurídicamente independientes del mismo autor, infringiendo, por tanto, el $\S$ $155 \mathrm{StPO}$ (que dispone que la cognición y decisión de este debe limitarse exclusivamente al hecho descrito en la querella). ${ }^{121}$ En principio, difiero de esta crítica, ya que al igual que para la anterior bastaría con que jurisprudencialmente se estableciere como un estándar para su imposición la realización por el fiscal de una acusación suplementaria en el juicio oral, que la extienda a otros hechos [presumidos] del acusado (\$2 $266 \mathrm{StPO})$.

\section{iii) Decomiso ( $\$ \mathbb{S} 74-75 \mathrm{StGB})$}

Bajo su redacción original, el $\ 40$ del RStrG regulaba el decomiso de "cosas que han sido mostradas en ocasión de un delito, que han servido para su comisión o estaban destinadas a ellas". ${ }^{122}$ Era admisible su aplicación únicamente cuando el autor o partícipe del crimen o simple delito doloso se encontrare en posesión de la cosa (pena accesoria). Existía, no obstante, abundante regulación especial que complementaba esta regla general, ordenando el decomiso en caso de delitos imprudentes y/o de faltas, alterando la facultatividad de su imposición o determinando su aplicación con independencia de sobre quien recaiga la propiedad (basta la vinculación del objeto-hecho). La reforma introducida por la EGOWIG acabó con esta regulación fragmentaria, instaurando un "sistema de firmes principios generales" (que en el StGB se encuentran consagrados en los $\iint$ 74-76a., los que, sin embargo, no afectan las cuantiosas normas especiales existentes respecto del decomiso). ${ }^{123}$

El decomiso como pena accesoria ( $\int 40 \mathrm{RStrG}$ ) era únicamente aplicable sobre los objetos producidos por el crimen o delito doloso o cuya vigente composición (=configuración) sea atribuible a este (producta sceleris). Así, Frank, Maurach y Mezger. Su ejecución, por tanto, excluía tanto el objeto obtenido con la comisión del delito (=botín) como el objeto del hecho (v. gr. arma en delito de porte ilegal). Si bien para el caso del "botín" (=ganancias), habiendo entrado en vigencia el StGB, ello pareciere menos controvertible (el provecho obtenido del hecho está sujeto a la Verfall), en el período 1871-1974 su exclusión no se presenta de forma tan absoluta.

El término "objeto" en el RStrG, a diferencia del StGB, limita su comprensión exclusivamente a las cosas corporales, ${ }^{124}$ excluyéndose por tanto a los derechos. Al parecer, al excluir las cosas adquiridas mediante la acción punible,

120 Ibid.

121 ROXIN (2001), pp. 86-87.

122 Merkel (2004), p. 234.

123 MAURACH/GÖSSEL/ZIPF (1995), p. 680.

${ }^{124}$ JESCHECK (1981), p. 1103. 
estos autores no distinguen si aquellas fueron obtenidas directamente o si lo fueron mediante el uso de un producta sceleris.

El RStrG imponía el decomiso, asimismo, sobre aquellas cosas empleadas para la comisión del hecho punible (instrumenta sceleris). Los ejemplos brindados por Maurach denotan que es irrelevante el momento en que se utilizan dichos objetos, es decir, pueden ser decomisados incluso si lo fueren en los actos preparatorios o durante la etapa de agotamiento del delito, siendo relevante únicamente su efectiva utilización (lo que puede entenderse en oposición a destinado no empleado, como en el comiso como medida preventiva). Difiere de ello Frank, quien incluye dentro de los instrumentos aquellos objetos destinados a la comisión de un crimen o simple delito y no utilizados y, excluye, a su vez, aquellos empleados para su preparación, para esconderlos o para posibilitar la fuga. A su vez, para el vigente StGB, Maurach/Gössel/Zipf señalan que el decomiso también puede imponerse para la realización de actos preparatorios o de participación autárquicamente punibles, es decir, a pesar de no concurrir principio de ejecución.

Finalmente, es y ha sido un entendimiento bastante asentado el que el decomiso se impone sobre bienes utilizados como "medios" para la comisión del hecho, por lo que deben excluirse aquellos objetos cuyo uso se encuentra comprendido en el supuesto de hecho de la norma (v. gr. puede ser decomisada como instrumento el arma del homicida, mas no la que el autor portaba careciendo de licencia). Asimismo, existe una regla de rigor que determina que no procede imponer el decomiso no obstante concurrir todos sus presupuestos cuando esta medida sea desproporcionada en relación con el hecho (a no ser que haya sido establecido de forma preceptiva). Además, el tribunal puede disponer que el decomiso permanezca en suspenso en los casos de los $\iint 74$ y $74 a$. StGB cuando su finalidad pueda ser alcanzada por medio de otra medida menos intrusiva.

\section{iii.1) Clases de decomiso}

(1) Decomiso punitivo (relacionado con el interviniente): este exige para su imposición, por regla general en la sentencia penal (excepción \76a. StGB), ${ }^{125}$ que recaiga sobre cosas o derechos que pertenecen al autor o partícipe y que la realización del hecho sea culpable y dolosa. Supone, asimismo, una sanción adicional a estos últimos.

Se debate si lo determinante es la pertenencia jurídica o económica de la cosa o derecho al patrimonio del autor o partícipe. La doctrina mayoritaria se inclina por la segunda, es decir, sin importar el potencial perjuicio que puede sufrir el verdadero dueño (para quien se puede decretar una indemnización) lo

125 Véase Roxin (2001), pp. 548-549. 
determinante es que el autor puede disponer económicamente de la cosa, sancionándose, por tanto, a quien efectivamente la utilizó. ${ }^{126}$

Es relevante, a su vez, la medida de decomiso de valor equivalente ( $\int 74 \mathrm{c}$. StGB). Dispone esta regla que el tribunal puede decretar el decomiso de una suma de dinero contra el autor o partícipe hasta por una cuantía que corresponda al valor de la cosa en vez de proceder sobre esta última (sanción patrimonial). Lo precedente es consecuencia de que la ley exige que esta medida recaiga sobre cosas o derechos que pertenecen al autor o partícipe, quienes por tanto, si no existiere una regulación como esta, podrían impedir su cumplimiento mediante enajenación o consumo.

Finalmente, de forma excepcional se permite la imposición del decomiso punitivo de objetos pertenecientes a terceros cuando estos hubieren contribuido al menos imprudentemente a la utilización de dichos objetos en el hecho delictivo; o cuando aquellos hayan sido obtenidos por el tercero con conocimiento de las circunstancias que permiten la imposición del comiso ( $\$ 74 \mathrm{a}$. StGB). Puede imponerse también sobre la propiedad de personas jurídicas si se cumplen los presupuestos establecidos en el $\int 75 \mathrm{StGB}$.

(2) Decomiso de aseguramiento (indiferenciado): producto de su finalidad preventiva, este se impone sin tomar en consideración que recaiga o no sobre cosas o derechos que pertenecen al autor o partícipe -no obstante que cuando se aplica sobre objetos pertenecientes [jurídicamente] a terceros, el $\int 74 \mathrm{f}$. (1) StGB prevé una indemnización ascendente al valor de mercado del objeto-, ni tampoco que la realización del hecho sea culpable. Procede, a su vez, cuando dichos objetos conforme a su naturaleza y circunstancias concretas ponen en peligro a la sociedad o a una persona en particular ${ }^{127}$ (v. gr. veneno) o respecto de los cuales existe el riesgo cierto de que sean empleados para la realización de delitos futuros (v. gr. un arma).

Si bien, conforme a las reglas generales, es de carácter facultativo para el tribunal, existen múltiples disposiciones especiales que lo establecen de forma preceptiva.

\section{Regulación general del comiso en Chile}

Habiendo elucidado el sentido y alcance de la sanción de comiso en la regulación comparada, es preciso determinar el tratamiento que ha recibido esta en el derecho chileno, a fin de determinar qué elementos es posible hacer extensivos de aquella a este.

${ }^{126}$ JESCHECK/WEIGEND (2002), p. 859.

127 Ibid., p. 851. 


\section{a) Alcance del término "instrumentos"}

No existe discusión en cuanto al alcance de los instrumenta sceleris. Es uniforme la doctrina al señalar que corresponden a los medios con los que se ejecutó el delito. ${ }^{128-129}$ De lo precedente, asimismo, se colige que el decomiso de los instrumentos excluye cualquier objeto no utilizado directamente en el delito sometido a proceso, ${ }^{130}$ no obstante tener el tribunal la certeza de su utilización en otro hecho delictivo distinto.

Como el comiso se impone sobre bienes utilizados como medios para la comisión del injusto, deben excluirse aquellos objetos cuyo uso se encuentra comprendido en el supuesto de hecho de la norma de sanción (v. gr. tenencia de instrumentos destinados conocidamente para efectuar el delito de robo, del artículo $445 \mathrm{CP}$ ). Para la determinación de estos medios, a su vez, la condictio sine qua non es necesaria pero no suficiente, por cuanto produciría una extensión desmesurada del concepto, debiendo comprender este únicamente los que fueron empleados o se encuentran relacionados con las acciones a las que son objetivamente imputables la realización del delito (principio de proporcionalidad). Por tanto (v. gr.), si opuestamente a lo señalado, entre otros, por Buchheister, ${ }^{131}$ se admitiera el comiso de bienes inmuebles, ${ }^{132}$ debería procederse al decomiso del laboratorio de anfetaminas, mas no al del local donde frecuentemente se hacía la tradición de las dádivas al funcionario público.

\section{b) Alcance del término "efectos"}

Conforme al artículo $31 \mathrm{CP}$, el comiso recae sobre los efectos que provengan del delito y sobre los instrumentos que fueron utilizados en su ejecución. El uso del vocablo " $y$ " determina que todo instrumento nunca es efecto. El primer inconveniente se origina al precisar qué elementos se encuentran comprendidos dentro del término "efectos". Al respecto, podemos vislumbrar cinco grupos de posturas:

i) Quienes como Labatut entienden por ello "los objetos o el dinero de que se apropió el delincuente", ${ }^{133}$ equiparando, por tanto, efecto del delito a objeto material del hecho. ${ }^{134}$

128 Así, Corte Suprema. Recurso de queja de Martín Petersen y otro (1941). G.T. 1941-2, pp. 57-241.

${ }^{129}$ En sentido opuesto: Corte de Apelaciones de Santiago contra Anselmo Martínez y otros (1952). RDJ XLIX, 4-85.

130 Así, Corte de Apelaciones de Coyhaique (resolución $N^{\circ}$ 3778), Rol 46-2012, de fecha 30 de julio de 2012.

131 BuCHHeister (1944), p. 30. Así también: GuZMán (2009), p. 337.

132 Así, por ejemplo, el artículo 45 de la ley 20.000 y el artículo $97 \mathrm{~N}^{\circ} 9$ del Código Tributario.

133 LABATUT (1979), p. 293.

${ }^{134}$ Lo relevante de esta definición es el verbo utilizado: “apropió”, el cual él mismo define como sustracción de una cosa con ánimo de señor y dueño (LABATUT (1983), pp. 185-186) lo que sugiere 
ii) Quienes como Guzmán Dalbora, ${ }^{135}$ Hernández $^{136}$ y Suárez ${ }^{137}$ entienden que producta sceleris son exclusivamente aquellas cosas que tienen su origen en el delito, o que le deben su composición actual a este, excluyendo, por tanto, al objeto del delito (objectum sceleris) (v. gr. dinero falsificado, en oposición a dinero [ajeno] apropiado). ${ }^{138} \mathrm{Si}$ bien podría respaldarse esta postura en la constante oposición/distinción entre dinero y efectos que realiza el legislador (v. gr. en los artículos 279 y $470 \mathrm{~N}^{\circ} 1 \mathrm{CP}$ ), aparece esto como excesivo, ya que, a diferencia del RStrG, no existe tal restricción en el ordenamiento legal chileno.

Refuta esta postura, de forma expresa, tanto la Corte Suprema como Cousiño, quienes señalan, respectivamente:

[L] a noción de efecto del delito [...] no tiene relación con la noción de efecto como resultado de una causa precedente. Es errónea la tesis de que ba de haber una relación causal entre el delito y la cosa que de él surge o que con él se obtiene, y de la cual infiere el ocurrente que las cosas materias del contrabando no son efectos del mismo, dado que ellas existen desde antes. ${ }^{139}$

Los efectos del delito están constituidos por beneficios o ventajas de orden material, pues la ley se refiere a los efectos en el sentido jurídico económico del término y no a su acepción de resultado que se sigue a una causa. ${ }^{140}$

iii) Quienes como Etcheberry, Cury, Garrido y Politoff extienden el ámbito de aplicación posible de los producta sceleris más allá de aquellos objetos cuyo origen material o su estructura actual es achacable al hecho punible ("que de él provengan"). Esta aseveración se basa tanto en los conceptos que elaboran ("[1]os efectos del delito [...] son los objetos materiales sobre los cuales haya recaído la acción delictiva o que sean producto de ella"), ${ }^{141}$ como en los ejemplos con que materializan estos. A su vez, es sencillo vislumbrarlo en la crítica que realizan sobre algunos tipos delictivos especiales en los que el legislador ha consignado que los objetos del delito deben ser decomisados (v. gr. en los delitos de cohecho y tráfico ilícito de estupefacientes), calificándolos como disposiciones inútiles que constituyen errores de técnica legislativa. ${ }^{142}$

pensaba en delitos como los de hurto, apropiación indebida o abigeato (atentados contra la propiedad en general).

135 GUZMÁN (2009), p. 336.

136 HERNÁNDEZ (2011), p. 484.

137 SUÁREZ (2000), pp. 497 y 502.

138 En idéntico sentido: Corte Suprema. Recurso de queja de Martín Petersen y otro (1941). G.T. 1941-2, pp. 57-241.

139 Corte Suprema contra Verdugo, Jorge y otros (recurso de casación en el fondo). 06 de junio de 1969. Revista de Derecho y Jurisprudencia, Segunda Parte, Sección Cuarta, p. 119 (considerando $11^{\circ}$ ). 140 COUSIÑO (1975), p. 296.

141 ETCHEBERry (1998), p. 167. Véase también: CURY (2005), p. 751; GARRIDO (2001), p. 300; Politoff (2002), p. 286.

142 Así: NovoA (2005), p. 344; Cury (2005), p. 751; ETCHEBERry (1998), p. 167. 
Lo anterior, en rigor, no es acertado. Si se considera de forma absoluta la regla del $31 \mathrm{CP}$, que prohíbe decomisar los objetos que pertenezcan a terceros no responsables, bienes como las "especies sustraídas" (fundamentalmente título IX, $\$ 1$ a $\$ 4 \mathrm{CP}$ ) no pueden ser comprendidas como efectos del delito (no obstante ser parte de la responsabilidad civil). Esto es respaldado por la teoría del bien jurídico, en virtud de que, al sustraer el ofensor el objeto material de la acción, solo priva al ofendido de la posibilidad de acción/utilización sobre/de la cosa. ${ }^{143}$ Es decir, conserva este la misma calidad bajo la tenencia/posesión del bien por el ladrón, ${ }^{144}$ lo que implica afirmar que la propiedad [civil] se mantiene [al menos temporalmente] incólume, siendo solo lesionada la gewabrsam, es decir, el "contenido de poder fáctico correlativo a la posición jurídico formal de propietario" ${ }^{145}$ (delito de lesión) y no la posición jurídico-formal en sí. ${ }^{146}$ Por tanto, pervive la acción restitutoria y la acción reivindicatoria (esta última en caso de cosas no fungibles), hasta que, discutiblemente, opere la prescripción adquisitiva.

En razón de todo lo precedente, el objeto de la acción [por regla general] pertenecerá a un tercero no responsable. ${ }^{147}$ Sin embargo, como la ley no exige acreditar que la cosa pertenezca al autor, esta objeción deviene en irrelevante, ya que siempre será procedente el comiso en estos casos, a no ser que un tercero acredite la propiedad sobre el bien (imponiéndose, v. gr., sobre bienes apropiables no apropiados - res nullius y res derelictae - y sobre bienes apropiables apropiados de los cuales se ignora a su propietario). Esto debe complementarse, además, con el hecho de que al pronunciarse la sentencia definitiva la restitución no implica devolver la cosa a quien tenía la tenencia al momento de su incautación, sino que a quien pruebe haber ejercido dicha tenencia en el momento en que se cometió el injusto $^{148}$. Tenían claridad acerca de esto: Robustiano Vera ("lo que el reo pierde es

143 Véase Knut Amelung: “El concepto «Bien Jurídico» en la teoría de la protección penal de Bienes Jurídicos” en: HEFENDEHL (2007), p. 243.

144 Así también: Corte Suprema con Evaristo Zepeda Araya (y otros), Rol 4359-2005. "El comiso del vehiculo inscrito a nombre de un tercero no prosperará ya que los argumentos presentados no son suficientes para desvirtuar la presunción de dominio que emana de la referida inscripción, de tal manera que dicho vehiculo se encuentra en la situación de excepción prevista en la parte final del artículo 31 del Código Penal siendo entonces improcedente considerarlo entre las especies afectadas por la pena accesoria que establece dicha norma" (considerandos $4^{\circ}, 7^{\circ}, 9^{\circ}, 10^{\circ}$ ).

145 BASCUÑ́́N (2007b), p. 9.

146 Véase BASCUÑÁN (2007a), pp. 12-13.

147 Un ejemplo claro de los efectos adversos que devienen de la inclusión de los objetos dentro de los efectos es el caso "Agosi con Reino Unido" (TEDH, 24 de Octubre de 1986). Fallo disponible en: VERVAELE (1998), pp. 72-73.

${ }^{148} \mathrm{La}$ extensión factual no es aleatoria, ya que, si bien el artículo 189 CPP preceptúa que el juez de garantía declarará el derecho del reclamante (víctima o tercero) sobre dichos objetos, esa declaración solo puede referirse a situaciones de hecho, es decir, "la simple posesión o tenencia material de los bienes reclamados, sin que el juez de garantía pueda pronunciarse sobre algún otro título del reclamante”. BARROS (2007), p. 952. Así también: HORVITZ/LÓPEZ (2004), p. 610; Corte Suprema (recurso de nulidad; resolución $\mathrm{N}^{\circ}$ 25.368), Rol 3731-2011, de fecha 10 de septiembre de 2008 ("[...] de la absolución del acusado, como aquí ocurrió, sin que se demostrase el dominio de los 
solo lo que le pertenece: lo robado es de su dueño") ${ }^{149}$ y Joaquín Pacheco ("[e]n cuanto a los efectos robados, nunca dejaron de pertenecer a su dueño, y a él deben volverse sin detención"). ${ }^{150}$

iv) Existe una cuarta postura, encabezada por Novoa, quien si bien adhiere a una teoría amplia, es esta más acotada que la anterior. Señala el autor:

[D]eben considerarse efectos provenientes del delito las cosas materiales que han resultado del hecho punible (moneda falsa, armas probibidas que se han fabricado, el dinero ganado en el juego de azar, etc.). ${ }^{151}$

No obstante lo insuficiente de esta teoría, tiene la virtud de que incluye dentro de efectos tan solo a aquellas cosas con origen en el delito y a aquellas que son al momento de su incautación de propiedad del autor, pero que fueron adquiridas del delito - con aquiescencia de quien tenía su posesión con anterioridad a la consumación de este-.

v) Finalmente, está la posición defendida en un fallo de la Corte Suprema (2012), la cual es la más amplia, por cuanto incluye dentro del alcance del artículo $31 \mathrm{CP}$ a las ganancias. En sus propios términos:

Que la novedad del régimen de comiso que estableció la ley especial $N^{\circ} 19.366$ con respecto al general consagrado en el Código Penal, es la designación en él de las drogas tóxicas, porque todos los demás bienes alli consignados constituyen precisamente los instrumentos o efectos del delito o las ganancias que de él derivan, de modo que no era necesaria su mención expresa, pues resultarian siempre decomisables de acuerdo a las reglas generales del estatuto punitivo.

Que, la sentencia impugnada, al excluir del comiso ciertos bienes por la exclusiva consideración que esa sanción resulta originaria en la Ley $N^{\circ}$ 19.366, importa un error de derecho por errada interpretación del articulo 27 de la Ley $N^{\circ}$ 19.366, unido a la falta de aplicación de la regla general del artículo 31 del Código Penal que en términos perentorios prescribe que toda pena que se imponga por un crimen o un simple delito, lleva consigo la pérdida de los efectos que de él provengan y de los instrumentos con que se ejecutó, a menos que pertenezcan a un tercero no responsable del crimen o simple delito, cuyo no ha sido el caso, norma que a la data de los hechos estaba vigente por lo que su aplicación al caso de marras era obligatoria. ${ }^{152}$

bienes por parte de las Mineras Candelaria y Mantos de Oro y tampoco de ninguna otra persona, los bienes debían ser restituidos a quien aparecía como su legítimo tenedor, que en este caso era el mismo acusado").

149 VERA (1883), p. 187.

150 PACHECO (1888), p. 372.

151 NovOA (2005), p. 344.

${ }^{152}$ Corte Suprema contra Carlos Silva Leiva y otros (recurso de casación en el fondo; resolución $\mathrm{N}^{\circ}$ 51.297). Rol 7840-2010, de 25 de junio de 2012 (considerando 24 y 25). 
Es decir, lo que la Corte Suprema sostuvo, a efectos de sortear supuestos problemas de irretroactividad de la ley penal, es que el artículo $31 \mathrm{CP}$ incorpora dentro de su ámbito de aplicación a los efectos provenientes de delito y a las utilidades que bubieren originado, cualquiera sea su naturaleza jurídica o las transformaciones que bubieren experimentado, por lo que su explicitación en el artículo 27 de la ley 19.366 deviene en superflua, pues se encuentran comprendidas dentro de las reglas generales.

Dicho entendimiento se ve replicado por la Corte de Apelaciones de Rancagua, la que en un fallo reciente (2014) sostuvo:

Que por otra parte, lo que sí resultó establecido es que el imputado adquirió, con las tarjetas sustraidas cuatro llantas de vebiculos, especies que si pueden ser consideradas como un producto del ilícito, por lo que se decretará el comiso solo respecto de ellas. ${ }^{153}$

Se pronunció en idéntico sentido, asimismo, la Corte de Apelaciones de Valdivia (2013), que determinó la imposición del comiso de un inmueble inscrito a nombre de la condenada, debido a que su adquisición fue financiada en parte relevante (no en su totalidad) con dineros conseguidos mediante el delito de obtención fraudulenta de prestaciones improcedentes en perjuicio del fisco (fraude de subvenciones, artículo $\left.470 \mathrm{~N}^{\circ} 8 \mathrm{CP}\right)$. En sus propios términos:

Que, asimismo, se rechazará la alegación de la inaplicabilidad del comiso o pérdida de los instrumentos o efectos del delito. [...] Los instrumentos del delito se han definido como los medios materiales empleados por el autor para cometer el delito. Los efectos del delito, por su parte, corresponden a los elementos materiales con que el sujeto activo se ha beneficiado tras su perpetración.

Asi las cosas, no cabe duda que la propiedad adquirida por la imputada, se corresponde a las hipótesis previstas en el artículo 31 del Código Penal que autorizan el comiso o pérdida de los efectos del delito y de los instrumentos con que se ejecuto. ${ }^{154-155}$

\footnotetext{
153 Corte de Apelaciones de Rancagua (resolución N²0.257), Rol 130-2014, de 8 de abril de 2014. 154 Corte de Apelaciones de Valdivia, Rol 431-2013, de fecha 17 de septiembre de 2013.

155 En sentido contrario, sin embargo, el voto de minoría de los ministros Hugo Dolmestch y Lamberto Cisternas, quienes conociendo del recurso de queja interpuesto por la defensa en contra de los integrantes de la Corte de Apelaciones de Valdivia (resolución No 123.183, Rol 7859-2013, de fecha 16 de diciembre de 2013), sostuvieron una tesis restrictiva, similar a la de Novoa. En sus propios términos: "Respecto de la pena de comiso consideran los disidentes que es improcedente su imposición en los términos que ha sido determinada en el fallo, porque el inmueble no es un instrumento del delito, es decir, parte de los medios materiales empleados para la comisión del hecho delictivo, o un efecto que provenga de él, entendiendo por tal el producto del delito o el objeto sobre el que recae. Solo es efecto del delito en este caso la prestación indebidamente obtenida -equivalente al subsidio de $330 \mathrm{UF}$ - y que corresponde al perjuicio económico que se causa al Fisco o a las instituciones que señala el artículo $470 N^{\circ} 8$ del Código Penal, por lo que pretender hacer efectiva dich a pena sobre otros bienes o valores equivalentes, se aparta de los términos del artículo 31 del Código Penal'. Así también:
} 
Finalmente, tuvo idéntica comprensión del alcance del término "efectos", la Corte de Apelaciones de Santiago (1964). En sus propios términos:

No pueden considerarse efectos del delito, en el caso, las especies materiales sustraídas, o sea, los billetes en sí mismos, sino los bienes que los reemplazan en caso de inversión. ${ }^{156}$

En derecho comparado es tradicional la afirmación de que el comiso de ganancias tiene su fundamento en el enriquecimiento injusto (acción in rem verso). Ello es innegable: una y otra institución se sustentan en la existencia de un enriquecimiento patrimonial sin fundamento jurídico. En efecto, difieren ambas solo gradualmente: el comiso de ganancias solo procede por la ejecución de un delito y el enriquecimiento sin causa, en cambio, para cualquier desplazamiento patrimonial (= atribuciones) realizado sin que exista una causa que lo justifique ${ }^{157-158}$ (idea de justicia conmutativa: centra su atención en el enriquecido, no en la víctima, por lo que se aplica con independencia del empobrecimiento correlativo del demandante). ${ }^{159}$

Ahora bien, conforme a la falta de una previsión general que las consagre, cabe preguntarse si es posible que los producta sceleris sean no solo aquellas cosas efectivamente producidas por la acción criminal, sino que también las ganancias provenientes de la misma, como se afirma en los fallos previamente citados. Para responder lo precedente, debe tenerse en consideración las fuentes de las que deriva la regulación del comiso: el artículo $31 \mathrm{CP}$ es tomado con leves variaciones del artículo 59 del Código Penal español de 1848 (1850), el que se mantuvo, a su vez, prácticamente incólume en el Código Penal de 1944 (1973). ${ }^{160}$ Respecto de

COUSIÑO (1975), p. 298: "No pueden extenderse [los efectos del delito], por ende, indefinidamente a todos los provechos o beneficios que, eventualiter, pudieren seguir produciéndose, como la herencia que se recibe inesperadamente por el homicidio de la víctima; ni, tampoco, las ganancias obtenidas de las especulaciones realizadas con el dinero burtado".

${ }^{156}$ Corte de Apelaciones de Santiago. RDJ, tomo LXII, $2^{a}$ parte, sección 4a , p. 253.

${ }^{157}$ El Código Civil chileno no obstante regular acciones específicas de enriquecimiento (v. gr. pago de lo no debido) no consagra un principio general de enriquecimiento sin causa (y menos de una acción de aplicación general). A pesar de ello, tanto la doctrina como la jurisprudencia lo han reconocido tanto como un principio general del derecho, como una fuente autónoma de las obligaciones.

${ }^{158}$ Difieren, asimismo, en que el estándar de convicción exigido para el tribunal en los procedimientos civiles (artículo $428 \mathrm{CPC}$ ) es manifiestamente más laxo que en materia penal (artículo $340 \mathrm{CPP}$, “más allá de toda duda razonable"). "De allí que pueda absolverse en sede penal y condenarse por las consecuencias civiles que produjo el hecho" (HORVITZ/LÓPEZ (2004), p. 604).

159 PeÑallillo (1996), p. 75.

160 Artículo 59 del Código Penal español de 1848 (1850). Toda pena que se imponga por un delito lleva consigo la pérdida de los efectos que de él provengan y de los instrumentos con que se ejecute [...]; Artículo 63 del Código Penal de 1870. Toda pena que se impusiere por un delito llevará consigo la pérdida de los efectos que de él proviniesen y de los instrumentos con que se bubiere ejecutado [...] y; Artículo 48 del Código Penal español de 1944 (1973). Toda pena que se impusiere por un delito llevará consigo la pérdida de los efectos que de él provinieren $y$ de los instrumentos con que se bubiere ejecutado [...]. 
este último, señala Puig Peña -con un argumento totalmente extensible a la regulación chilena actual- que no obstante que el comiso de ganancias fue regulado recién de forma expresa y especial en 1988, este era aplicable, por cuanto:

Propiamente el verdadero producto del delito está integrado por el objeto con que directamente o indirectamente se beneficia el culpable. Así, pues, al lado de los supuestos anteriormente descritos, los producta sceleris, por regla general, se integran por todas aquellas cosas que entran en el patrimonio del ofensor, constituyendo un enriquecimiento ilícito a costa del empobrecimiento de la persona que resulta perjudicada por la infracción. Y todo esto, bien en el caso de que el aumento del patrimonio del sujeto activo se verifique por la entrada de la misma cosa o efectos del delito, que por la entrada de aquellas otras que ha conseguido el culpable por permuta o con dinero procedente de la infracción. [...] [N]o puede limitarse [...] pues subsiste igual motivo respecto de cualquier provecho obtenido mediante la acción criminosa. ${ }^{161}$

\section{c) Necesaria extensión de la aplicación del comiso de ganancias en la} regulación del Código Penal chileno (=conclusión)

No obstante que la doctrina chilena -a diferencia de los autores españoles de época- no ha respaldado una tesis extensiva del término "efectos", la Corte Suprema y las Cortes de Apelaciones de Rancagua, Valdivia y Santiago, como ya se expuso, sí lo han hecho, pudiendo ello sustentarse dogmáticamente en al menos cuatro supuestos:

i) Por el sentido del artículo $17 \mathrm{~N}^{\circ} 1 \mathrm{CP}$, el que asimila "efecto" a "provecho", por lo que es prudente entender que este último concepto es idéntico [en su sentido y alcance] al del artículo $31 \mathrm{CP}$, mas que se encuentra restringido por la disímil finalidad de ambos. El fin de la norma es castigar a quien "se aprovecha", situación que se determina según la relación entre el aprovechamiento [secundario] y el delito principal [el cual se comete para aprovecharse del objeto material vía agotamiento]; no castigar según qué tan directamente de una causa [delito principal] deriva determinado objeto (el artículo $17 \mathrm{CP}$ no señala las circunstancias especiales que hacen del encubrimiento algo punible ni tampoco circunscribe de forma alguna el alcance del concepto "efectos").

A mayor abundamiento, es encubridor quien, concurriendo los requisitos del inciso I del artículo $17 \mathrm{CP}$, se "aprovecha" por sí mismo o facilita a los hechores medios para que se "aprovechen" de los efectos del delito. Señala Cury que "[a]provechar significa obtener una utilidad o ganancia de naturaleza económica" ${ }^{\text {"162 }}$ y Etcheberry precisa, a su vez, que por efectos [en el

161 PUIG (1952), p. 456. 
aprovechamiento] "se entiende el objeto material del mismo y lo anexo a él" "163. Sin embargo, tanto Labatut ${ }^{164}$ como Novoa ${ }^{165}$ extienden al objeto sustitutivo (=ganancias) el alcance del restringido concepto de "efectos" de la receptación dado por Etcheberry (considerando, por tanto, encubridor a quien recibe el dinero que el autor ha obtenido de la venta de la cosa robada).

Si bien la identidad de significados de la locución "efectos" para ambas disposiciones no es pacífica, tiene semejante entendimiento, Cousiño. ${ }^{166}$

ii) Porque una interpretación literal de la regla del artículo $31 \mathrm{CP}$ no determina una aplicación restrictiva de la locución "efectos que de él provengan". No es categorialmente necesaria la asimilación doctrinaria de los términos "provengan" y originen (que determina la exclusión de la aplicación del comiso de ganancias), encontrándose Chile, por tanto, en idéntico estado a la España anterior a la entrada en vigencia del Código Penal de 1995, en la cual la inmanencia de los provechos a los efectos era, al menos, debatida.

A su vez, respecto de la naturaleza jurídica de pena del comiso (cuya finalidad preventiva no se opone a la evitación de un enriquecimiento injusto), su ubicación geográfica la hace indubitada ("[p]enas que llevan consigo otras accesorias"). Su carácter de pena pecuniaria, asimismo, es consecuencia evidente del término "pérdida" acuñado por la propia disposición. Esto tiene consecuencias determinantes únicamente para la extensión del comiso de ganancias (no para su procedencia), pues (ii.1) prescribe que su imposición precisa del cumplimiento de la estructura delictiva tripartita compuesta por los dos niveles de reglas de comportamiento y reglas de imputación, lo que implica la necesaria imputación del hecho antijurídico a la culpabilidad de su autor (posdelictividad); (ii.2) determina que si no concurre una nueva figura típica (que tenga o no antecedente en el injusto anterior), no se permita su adscripción a terceros no responsables, por cuanto solo se puede responder penalmente por hechos propios, no por los ajenos (principio íntimamente conectado con el de culpabilidad por el hecho). Relativiza lo anterior, sin embargo, el alcance de la expresión "pertenezcan" del artículo 31 $\mathrm{CP}$, ya que la relación del objeto con el autor es negativa, pues no es que la cosa deba pertenecerle a este sino que no debe pertenecerle a otro (la ley no exige acreditar el dominio del interviniente sobre la cosa; dispone, en cambio, que los terceros sí lo hagan) y; (ii.3) consagra que la valoración como prueba de cargo de aquello que legalmente no tiene el carácter de tal da lugar al recurso de nulidad, lo que para el caso en cuestión implica que no existe nunca una carga del acusado de probar el origen lícito de su patrimonio.

163 ETCHEBERRY (1998), p. 103.

164 LABATUT (1983), p. 204.

${ }^{165}$ NOVOA (2005), p. 196.

166 COUSIÑO (1975), pp. 296-297. 
iii) La redacción original del artículo $60 \mathrm{CP}$ (modificado por la ley 11.625 de 1954, que incluyó la regulación del producto del comiso, equiparándolo al de la multa, es decir, transfiriendo la propiedad de los bienes que se le despojaron al condenado al fisco), en la que el destino del dinero obtenido del hecho punible, así como el producto de la enajenación en pública subasta, era utilizado para solventar las responsabilidades civiles del condenado o de quien respondía por él, conforme al orden establecido en el artículo $48 \mathrm{CP}^{167}$ (equiparando, por tanto, el comiso al restablecimiento de una ventaja injustamente obtenida, ya que, lo que ha pasado a dominio fiscal no puede, al mismo tiempo, servir para indemnizar perjuicios). ${ }^{168}$ En términos de Pacheco:

La ley no dice aqui lo que se ha de hacer con esos efectos, ó con ese decomiso; pero claro está que se ba de bacer lo que con todos: atender á las responsabilidades pecuniarias, segun el órden establecido en otro articulo, y aplicar al fisco lo que sobrare, si alguna cosa sobrase de ellas. ${ }^{169}$

iv) Por la propia historia fidedigna del establecimiento de la sanción de comiso en las leyes especiales creadas para combatir la criminalidad económica. Así, por ejemplo, en el proyecto de ley de responsabilidad penal de las personas jurídicas presentado por el ejecutivo (historia de la ley $\mathrm{N}^{\circ} 20.393$, p. 16), se explicitó que el artículo $31 \mathrm{CP}$ incluye dentro de su rendimiento conceptual a las ganancias. ${ }^{170} \mathrm{En}$ sus propios términos:

Articulo 14.- Sanciones accesorias. Se aplicará, accesoriamente a las sanciones señaladas en los artículos anteriores, las siguientes: [...]

b) Comiso. El comiso de las ganancias obtenidas por la persona jurídica como resultado del delito y demás efectos, objetos, documentos e instrumentos del mismo, según lo dispone el Código Penal.

Por tanto, en oposición al rendimiento conceptual mezquino que la doctrina y la práctica jurisprudencial chilena han dado a la expresión "efectos", este artículo demuestra la plausibilidad de que dentro de ellos no solo se encuentren comprendidos los objetos originados en la perpetración del delito, sino que se extiendan también a todas aquellas ganancias derivadas del mismo, limitado ello -de forma sustantiva- esencialmente por el principio de legalidad (lex stricta), el

167 Véase VERA (1883), p. 187.

168 Corte Suprema contra Alejandro Cubillos Pizarro, 25 de Abril de 1973 (casación en el fondo), Cita online: CL/JUR/24/1973 (Legal Publishing), p. 3. Para un razonamiento similar, en el caso de la regulación especial del comiso en la Ordenanza de Aduanas, véase Corte de Apelaciones de Iquique contra Mercedes Inostroza (1953). RDJ L, 4-81 y; Corte Suprema. Fisco contra Cuevas (1953). RDJ L, pp. 4-17. Véase, asimismo, ETCHEBERRY (1987), pp. 183-187.

169 PACHECO (1888), p. 374.

170 Véase SÁNCHEZ (2013), pp. 165-166: “Todo esto, según si se interpretare la remisión al Código Penal como comprensiva de toda la oración (i.e. tanto de las 'ganancias' como de los 'efectos' e 'instrumentos"”. 
que determina la improcedencia de ciertas variaciones del comiso de ganancias que precisan de consagración legal expresa, al encontrarse fuera del sentido literal posible del texto del artículo $31 \mathrm{CP}$. Es más, la mayor objeción que debe sortear esta interpretación extensiva es su similitud con la pena de confiscación. La diferencia, no obstante no ser de carácter estructural, se advierte en todo caso como manifiesta: su gradualidad. El comiso de ganancias es una especie de confiscación, donde, en oposición a la eficiencia no discriminatoria de esta última, se remite por mandato legal únicamente a bienes vinculados con el hecho punible (se debe probar fehacientemente que la ventaja patrimonial proviene del hecho delictivo objeto de la investigación). 


\section{BIBLIOGRAFÍA}

* Aguado, Teresa (2000): El comiso. (Edersa. Madrid). (2003): "La regulación del comiso en el Proyecto de Modificación del Código Penal” en: Revista Electrónica de Ciencia Penaly Criminología, N 5.

* Amelung, Knut (2007): "El concepto «Bien Jurídico» en la teoría de la protección penal de Bienes Jurídicos” en: La Teoría del Bien Jurídico (Hefendehl, ed.), (Marcial Pons, Ediciones Jurídicas y Sociales S.A., Madrid).

* Bacigalupo, Silvina (2202): "El comiso de ganancias procedentes de delitos: artículo 127 del Código Penal" en: Ganancias ilícitas y Derecho Penal. (Ed. Universitaria Ramón Areces. Madrid).

* Barros, Enrique (2007): Tratado de responsabilidad extracontractual. (Ed. Jurídica de Chile. Santiago).

* Bascuñán, Antonio (2007a): Delitos contra la propiedad (2). Delitos de expropiación con apropiación correlativa. Primera parte: El Sistema de los Delitos de apropiación. Material de estudio para el curso de Derecho Penal (Parte Especial), Universidad Adolfo Ibáñez.

(2007b) Delitos contra la propiedad (3). Delitos de apropiación con ruptura de la custodia ajena. Material de estudio para el curso de Derecho Penal (Parte Especial), Universidad Adolfo Ibáñez.

(2007c) Derechos fundamentales y Derecho penal, en: Revista de Estudios de la Justicia, № 9.

* Baumann, Jürgen (1986): Derecho Procesal Penal. Conceptos fundamentales y principios procesales. (Ediciones De Palma. Buenos Aires).

* Blanco, Isidoro (2007): La aplicación del comiso y la necesidad de crear organismos de recuperación de activos, en: Revista electrónica de la Asociación Internacional de Derecho Penal (ReAIDP / e-RIAPL), A-01.

* Buchheister, Germán (1944): El comiso. Memoria de prueba para optar al grado de licenciado en la Facultad de Ciencias Jurídicas y Sociales de la Universidad de Chile. (Santiago).

* Cazorla, Soledad (2004): "El comiso, ganancias procedentes del delito en relación con la sentencia de 29 de julio de 2002. Caso Banesto" en: Dogmática y ley penal, en: Libro homenaje a Enrique Bacigalupo. Tomo I. (López/Zugaldía, Coords), (Marcial Pons. MadridBarcelona).

* Climent, Carlos (2011): Código Penal. Jurisprudencia sistematizada. (Tirant lo Blanch, 4a ed. Valencia).

* Cobo del Rosal, Manuel (director) (2000): Comentarios al Código Penal. Tomo IV. Artículos 95 a 137. (Edersa. España).

* Conde-Pumpido, Cándido (director) (2004): Código Penal comentado. Tomo I. Artículos 1 a 318. (Boch, $2^{\mathrm{a}}$ ed. Barcelona).

* Córdoba Roda, Juan [et. al] (1976): Comentarios al Código Penal. Vol. II. Artículos 23 a 119. (Ariel. Barcelona).

* Cousiño, Luis (1975): Derecho Penal Chileno. Tomo I. (Ed. Jurídica de Chile, Santiago).

* Couso, Jaime; Hernández, Héctor (directores) (2011): Código Penal comentado. Parte General. Doctrina y jurisprudencia. (Abeledo Perrot, Legal Publishing Chile. Universidad Diego Portales, Santiago).

* Cury, Enrique (2005): Derecho Penal. Parte General. (Ediciones Universidad Católica de Chile, $8^{\mathrm{a}}$ ed. Santiago).

* Escuchurri, Estrella (2004): Teoría del concurso de leyes y de delitos. Bases para una revisión crítica. (Ed. Comares S.L. España).

* ESER, Albin (2006): “Observación preliminar a los $\iint 73$ y ss.” en: Strafgesetz̧buch Kommentar (traducción inédita de Antonio Bascuñán R.). (Schönke/Schröder/Cramer, Eds.) (Ed. C.H. Beck. München). 
* Etcheberry, Alfredo (1987): El Derecho Penal en la Jurisprudencia. Sentencias 1875-1966. Parte General y Especial. Tomo II. (Ed. Jurídica de Chile, $2^{\mathrm{a}}$ ed. Santiago).

(1988) Derecho Penal. Tomo II. (Ed. Jurídica de Chile, $3^{\mathrm{a}}$ ed. Santiago).

* Faraldo, Patricia (2008): "La regulación del comiso en España. Especial referencia a los comisos específicos en los delitos de tráfico de drogas, blanqueo de bienes y contrabando", en: Revista Peruana de Ciencias Penales, N 20.

* Fernández, Pilar (2000): "Comentario del Título VI. De las consecuencias accesorias" en: Comentarios al Código Penal. Tomo IV. Artículos 95 a 137. (Cobo del Rosal, Dir.), (Edersa. España).

* Ferrer, Antonio (1947): Comentarios al Código Penal, Tomo. II. (Sucesores de Nogués. Murcia).

* Garberí, José (director) (2006): Práctica jurisprudencial del Código Penal. Tomo I. (Boch, Barcelona).

* García, Percy (2006): "Las medidas aplicables a las personas jurídicas en el proceso penal peruano", en: Revista de Derecho. Universidad de Piura. Vol. 7, Perú.

* García-Pablos, Antonio (2005): Introducción al Derecho Penal. (Ed. Universitaria Ramón Areces, $3^{\text {a }}$ ed. Madrid).

* Garrido, Mario (2001): Derecho Penal. Parte General. Tomo I. (Ed. Jurídica de Chile. Santiago).

* Gracia, Luis (coordinador) (2004): Lecciones de consecuencias jurídicas del delito. (Tirant lo Blanch. Valencia). (2006) Tratado de las consecuencias jurídicas del delito. (Tirant lo Blanch. Valencia).

* Groizard, Alejandro (1872): El Código Penal de 1870. Comentado y concordado. Tomo II. (Editor Timoteo Arnaiz Burgos. Madrid).

* Guinarte, Gumercindo (1996): “Comentario al Título VI, De las consecuencias accesorias” en: Comentarios al Código Penal de 1995. Volumen I. (Vives Antón, Coord.) (Tirant lo Blanch. Valencia).

* Guzmán Dalbora, José L. (2009): La pena y la extinción de la responsabilidad penal. Primera parte. (Ed. B de F. Montevideo-Buenos Aires).

* Hefendehl, Roland (ed.) (2007): La Teoría del Bien Jurídico. (Marcial Pons, Ediciones Jurídicas y Sociales S.A., Madrid).

* Hernández, Héctor (2011): “Comentario al artículo 31 CP” en: Código Penal comentado. Parte General. Doctrina y jurisprudencia, (Couso/Hernández, Dirs.) (Abeledo Perrot, Legal Publishing Chile. Universidad Diego Portales, Santiago).

* Horvitz, María Inés y López, Julián (2004): Derecho Procesal Penal Chileno. Tomo II. (Ed. Jurídica de Chile. Santiago).

* Jescheck, Hans-Heinrich (1981): Tratado de Derecho Penal. Parte General. Volumen Segundo (traducción de Santiago Mir y Francisco Muñoz). (Ed. Bosch, $3^{\mathrm{a}}$ ed. Granada).

* Jescheck, Hans-Heinrich y Weigend, Thomas (2002): Tratado de Derecho Penal. Parte General (traducción de Miguel Olmedo). (Ed. Comares, $5^{\text {a }}$ ed. Granada).

* Labatut, Gustavo: Derecho Penal (1983): Tomo I. (Ed. Jurídica de Chile, 8 a ed. Santiago). (1983) Derecho Penal. Tomo II. (Ed. Jurídica de Chile. Santiago).

* López Barja de Quiroga y ZugaLdía, José Miguel (coordinadores) (2004): Dogmática y ley penal, en: Libro homenaje a Enrique Bacigalupo. Tomo I. (Marcial Pons. Madrid-Barcelona).

* LuZÓn, Diego (2004): "Las consecuencias accesorias como tercera vía de las sanciones penales" en: Estudios penales en recuerdo del profesor Vives Antón (Octavio/Gurdiel/Cortés, Coords.), (Tirant lo Blanch. Valencia).

* Manzanares, José Luis (1984): “El Comiso y la Caución en la propuesta de nuevo anteproyecto de Código Penal" en: Boletín de Información. Ministerio de Justicia e Interior, $\mathrm{N}^{\mathrm{o}}$ 1342, 1984, 38.

* Manzanares, José Luis; Albácar, José Luis (1990): Código Penal (comentarios y jurisprudencia). (Ed. Comares, $2^{\mathrm{a}}$ ed. Granada).

* Mapelli, Borja (1997): "Las consecuencias accesorias en el nuevo Código Penal”, en: Revista Penal, $\mathrm{N}^{\circ} 1$. 
* Maurach, Reinhart (1962): Tratado de Derecho Penal (traducción de Juan Córdoba). (Ed. Ariel. Barcelona).

* Maurach, Reinhart; Gössel, Karl y Zipf, Heinz (1995): Derecho Penal. Parte General. Tomo II. Formas de aparición del delito y las consecuencias jurídicas del hecho (traducción de Jorge Bofill G.). (Ed. Astrea de Alfredo y Ricardo Depalma, $7^{\mathrm{a}}$ ed. Buenos Aires).

* Merkel, Adolf (2004): Derecho Penal. Parte General (traducción de Pedro Dorado). (Ed. B de F. Montevideo-Buenos Aires).

* Mezger, Edmund (1958): Derecho Penal. Libro de Estudio. Parte General. (Ed. Bibliográfica Argentina. Buenos Aires).

* Mir, Santiago (1998): Derecho Penal. Parte General. (Ed. Reppertor, 5 a ed. Barcelona). (2004) "Una tercera vía en materia de responsabilidad penal de las personas jurídicas” en Revista Electrónica de Ciencia Penal y Criminología, 2004, Núm. 06-01, [disponible en internet:] http://criminet.ugr.es/recpc06-01.pdf.

* Novoa, Eduardo (2005): Curso de Derecho Penal Chileno. Parte General. Tomo II. (Ed. Jurídica de Chile, $3^{a}$ ed. Santiago).

* Octavio de Toledo y Ubieto, Emilio; Gurdiel, Manuel; Cortés, Emilio (coordinadores) (2004): Estudios penales en recuerdo del profesor Vives Antón. (Tirant lo Blanch. Valencia).

* Organización de Naciones Unidas (1993): Prevención del delito y la justicia penal en el contexto del desarrollo: realidades y perspectivas de la cooperación internacional, en: Revista Internacional de Politica Criminal ( $\left.\mathrm{N}^{\circ} 41\right)$.

* Pacheco, Joaquín (1888): El Código Penal. Comentado y concordado. Tomo I. (6a ed. Madrid).

* Peñallillo, Daniel (1996): "El enriquecimiento sin causa. Principio de Derecho y fuente de las obligaciones" en: Revista de Derecho y Jurisprudencia, Tomo XCIII, N² 2.

* Peris, Jaime/Plà, Cristina (2000): “Comentarios al Código Penal-Artículo 127” en: Comentarios al Código Penal. Tomo IV. Artículos 95 a 137. (Cobo del Rosal, Dir.), (Edersa. España).

* Politoff, Sergio (2002): Texto y comentario del Código Penal chileno. Tomo I. Libro PrimeroParte General. Artículos $1^{\circ}$ al 105 (Obra dirigida por POLITOFF, Sergio y OrTíz, Luis. Coordinador: MATUS, Jean P.). (Ed. Jurídica de Chile. Santiago).

* Politoff, Sergio; Matus, Jean P. (coordinadores) (2000): Gran criminalidad organizada y tráfico ilícito de estupefacientes. (Ed. Jurídica Conosur Ltda., Santiago).

* Puente, Luz María (2009): La regulación del comiso en el Código Penal español. Centro de Investigación Interdisciplinaria en Derecho Penal Económico.

* Puig, Federico (1952): “Comiso" en: Nueva Enciclopedia Jurídica (Director Mascareñas, Carlos). Tomo IV. (Ed. Francisco Seix. Barcelona).

* Quintero, Gonzalo (2010): "Sobre la ampliación del comiso y el blanqueo, y la incidencia en la receptación civil”, en: Revista electrónica de Ciencia Penal y Criminología, N 12-r2.

* Quintero, Gonzalo (director) y Morales, Fermín (coordinador) (2011): Comentarios al Código Penal español. Tomo I (artículos 1 a 233). (Aranzadi-Thomson Reuters, 6a ed. España).

* RAMÓn Ribas, Eduardo (2004): "La transformación jurídica del comiso: de pena a consecuencia accesoria” en: VV.AA. Estudios Penales y Criminológicos XXIV. (Servizo de Publicacións e Intercambio Científico Da Universidade de Santiago de Compostela. Da Universidade de Santiago de Compostela).

(2011): "Comentario al Título VI, De las consecuencias accesorias" en: Comentarios al Código Penal español. Tomo I (artículos 1 a 233), (Quintero y Morales, Coords.) (Aranzadi-Thomson Reuters, $6^{\mathrm{a}}$ ed. España).

* Roxin, Claus (1997): Derecho Penal. Parte General. Tomo I (traducción de Diego Luzón; Miguel Díaz y García Conlledo y Javier de Vicente). (Ed. Civitas, $2^{\mathrm{a}}$ ed. Madrid). (2001) Derecho Procesal Penal (traducción de Gabriela Córdoba y Daniel Pastor, revisada por Julio Maier). (Ed. Del Puerto S.R.L., 25a ed. Buenos Aires). 
* SÁnchez, Carlos (2013): Problemas de determinación de la pena en la ley $N^{\circ}$ 20.393. Memoria para optar al Grado Académico de Licenciado en Ciencias Jurídicas y Sociales. Santiago, Universidad de Chile.

* SChÖNKe, Adolf; SCHRÖDER, Horst; CRAMER, Peter (eds.) (2006): Strafgesetzbuch Kommentar (traducción inédita de Antonio Bascuñán R.). (Ed. C.H. Beck. München).

* Serrano, Ignacio (coordinador) (1998): Código Penal de 1995 (Comentarios y jurisprudencia). (Comares. Granada).

* SuÁrez, Christian (2000): “Análisis constitucional y legal de las penas de confiscación y comiso en el Código Penal y en la ley de estupefacientes” en: Politoff, Sergio; Matus, Jean P. (coordinadores). Gran criminalidad organizada y tráfico ilícito de estupefacientes. (Ed. Jurídica Conosur Ltda., Santiago).

* Unidad de AnÁlisis FinanCiero (UAF) (2012): Tipologías y señales de alerta de lavado de activos en Chile. Informe de condenas 2007-2011. (Santiago).

* Valero, Luis: Los bienes equivalentes y el riesgo de confiscación en la Ley de extinción de dominio y en el comiso penal, en: Revista Via Iuris, N6, 2009.

* Vera, Robustiano (1883): Código Penal de la República de Chile. Comentado. (Impr. De P. Cadot i Ca. Santiago).

* Vervaele, J.A.E (1998): “Las sanciones de confiscación: ¿Un intruso en el Derecho Penal?" (traducción de Lazo López/Moreno Moreno). Revista Penal Nº 2.

* Vives Antón, T.S. (coordinador) (1996): Comentarios al Código Penal de 1995. Volumen I. (Tirant lo Blanch. Valencia).

* Vizueta, Jorge (2007): "El comiso de las ganancias provenientes del delito y de otros bienes equivalentes a estas" en: Revista Penal $\mathrm{N}^{\circ} 19$.

* Welzel, Hans (1976): Derecho Penal Alemán. Parte General (traducción de Juan Bustos y Sergio Yáñez). (Ed. Jurídica de Chile. $11^{\mathrm{a}}$ ed (2 ed. castellana) Santiago).

* ZweIgert, Konrad y KÖTZ, Hein (2002): Introducción al Derecho Comparado (traducción Arturo Aparicio). (Colección Estudios Jurídicos, Oxford University Press). 